\title{
Natural Volatility, welfare and taxation
}

0. Posch and K. Waelde

Discussion Paper 2005-9

\section{Département des Sciences Économiques de l'Université catholique de Louvain}




\title{
Natural volatility, welfare and taxation
}

\author{
Olaf Posch $^{(a)}$ and Klaus Wälde ${ }^{(\mathrm{b}), 1}$ \\ ${ }^{(a)}$ University of Hamburg and ${ }^{(b)}$ University of Würzburg \\ CESifo and UCL Louvain la Neuve
}

March 2005

\begin{abstract}
Cyclical components are analytically computed in a theoretical model of stochastic endogenous fluctuations and growth. Volatility is shown to depend on the speed of convergence of the cyclical component, the expected length of a cycle and on the altitude of the slump. Taxes affect these channels and can therefore explain cross-country differences and breaks over time in volatility. With exogenous sources of fluctuations, a special case of our model, decentralized factor allocation is efficient. With endogenous fluctuations and growth, decentralized factor allocation is inefficient and (time-invariant) taxes can (de-) stabilize the economy. No unambiguous link exists between volatility and welfare.
\end{abstract}

Keywords: Endogenous fluctuations and growth, welfare analysis, taxation, stochastic continuous time model, Poisson uncertainty

JEL classification numbers: C65, E32, E62, H3, O33

\footnotetext{
${ }^{1}$ Olaf Posch: Department of Economics, University of Hamburg, 20146 Hamburg, Germany, olaf@poschs.com, http://www.poschs.com, Phone: + 49.40.42838 - 6924, Fax: + 49.40.42838 - 6314. Klaus Wälde: Department of Economics, University of Würzburg, 97070 Würzburg, Germany, klaus@waelde.com, http://www.waelde.com, Phone + 49.931.31-2950, Fax + 49.931.31-2671. We would like to thank Raouf Boucekkine, Peter Funk, Christian Kleiber, Ken Sennewald, Jonathan Schulz, Marcel Thum and Philippe Weil for discussions and seminar participants at various places for comments. This research is part of a programme supported by the Belgian government (Poles d'Attraction inter-universitaires PAI P5/21).
} 


\section{Introduction}

There is a considerable heterogeneity across OECD countries in the variance of annual GDP growth rates. This variance ranges from $25 \%$ and $15 \%$ for Greece and Japan in the 1961 to 1983 period down to $1.7 \%$ and $1.3 \%$ for France and Italy for 1984 to 2003 . Empirical studies show further that countries have breaks in their variance of growth rates over time (e.g. Kim and Nelson, 1999; McConnell and Perez-Quiros, 2000; Stock and Watson, 2003). Do these differences in volatility have only external causes such as terms of trade shocks, monetary or exogenous productivity shocks? Or is growth volatility of a country an endogenous, natural phenomenon of any growing economy and thereby also a function of various fundamentals of the economy under consideration, including economic policy? Stock and Watson (2003), surveying the literature on the "big moderation", attribute (roughly and with caveats) one quarter of the moderation in volatility in the US to improved policy, one quarter to good luck (lower volatility of productivity and commodity price shocks) and 50\% to "unknown forms of good luck".

This paper provides a theory of volatility that helps understanding some possible deeper reasons behind these various sources of volatility. It is part of a small but rapidly growing literature that integrates endogenous short-run fluctuations with endogenous long-run growth (e.g. Bental and Peled, 1996; Matsuyama, 1999; Wälde, 1999, 2002, 2005; Francois and Lloyd-Ellis, 2003; Maliar and Maliar, 2004, Phillips and Wrase, 2005²). It argues that volatility of a country can be viewed to be something natural, inherently linked to its growth process. As a consequence, volatility is just as endogenous as is the GDP growth rate. Sustained per-capita growth is obtained by R\&D causing jumps of technological frontiers (as in Aghion and Howitt, 1992 or Aghion, 2002). The resulting step function of labour productivity implies that growth and volatility can be traced back to the same source. ${ }^{3}$ In this setup, volatility and long-run growth result primarily (but not exclusively) from the introduction of new technologies. "Lower volatility of productivity" or "other unknown forms of good luck" can therefore be traced back to changes in fundamentals of the economy. As both long-run growth and short-run volatility are endogenous and therefore react to changes in policy, we can analyze to what extent policy changes affect volatility and growth at the same time or independently of each other. Understanding breaks over time for e.g. the US seems to require a break in volatility without a break in the growth trend (McConnell and Perez-Quiros, 2000). In a model without an explicit analysis of growth, such a simultaneous analysis would not be possible.

We analyze two measures of volatility: the variance of the growth rate of the economy, a widely used measure in empirical regression work (e.g. Ramey and Ramey, 1995), and

\footnotetext{
${ }^{2}$ These papers share the view that intentional investment into R\&D can not only explain long-run growth but also short-run fluctuations - without invoking exogenous disturbances to the economy. At the risk of simplifying too much, short-run fluctuations and long-run growth result from the introduction of more productive technologies as new technologies increase TFP by a discrete amount, similar to a step function, and not smoothly and continuously as in standard models. Due to the explicit modelling of R\&D processes, these models can be viewed to represent industrialized economies. Aghion, Banerjee and Piketty (1999) analyse an AK-type economy with borrowing constraints and investors and savers that are distinct agents. They find that when "the separation $<$ between investors and savers $>$ is large but not too large $\langle\ldots\rangle$ we observe short-run instability" (p. 1375). If the separation is too large, there would be a permanent slump. Without separation, the economy converges to balanced growth. Hence, their intermediate case with growth and fluctuations seems to best describe developing countries.

${ }^{3}$ Stochastic models of this theoretical literature therefore share Beveridge and Nelson's (1981) econometric view that trend and cycle are driven by the same shock, i.e. (here) jumps in the technological frontier.
} 
the coefficient of variation for cyclical components of time series, similar to those used in the RBC literature. It turns out that the variance of the growth rate does not - due to its complexity - lend itself to an intuitive theoretical analysis. Cyclical components have very simple moments, however, that reveal insightful relationships between model parameters and volatility. All measures are obtained analytically due to assuming a simple parameter restriction.

A question that arises immediately in a fluctuating economy asks whether higher or lower volatility should give rise to policy concerns. One possible answer to this question is a clear 'No'. The RBC approach is built (at least initially) on the belief that agents adjust optimally to a fluctuating world where markets are perfect and factor allocation is efficient (Kydland and Prescott, 1982; Long and Plosser, 1983) ${ }^{4}$. Lucas $(1987,2003)$ and others (surveyed in Lucas, 2003) show that, even in such a perfect world, welfare gains from removing all volatility do exist in principle (due to risk-aversion of households) but are quantitatively small. They amount to "about one-twentieth of 1 percent of consumption". ${ }^{5}$

The present paper argues that the belief that volatility per se is not an argument for welfare concerns in the Lucas sense is true indeed - as long as one beliefs that the engines of growth in an economy work under the absence of any imperfections as well. This assumption is implicit in standard RBC models where the growth process - in the Solow tradition - is viewed as exogenous. It is then easy to imagine indeed that in a perfectly competitive economy adjustment to exogenous disturbances takes place in an efficient way. This paper starts from the belief that (empirically speaking: at least to some extent) fluctuations in an economy are the result of the same type of technological progress that causes long-run growth. As the source of long-run growth and therefore short-run fluctuations is explicitly modelled, this endogeneity introduces various types of imperfections. Hence, if one believes that sources of growth are endogenous and taking the lessons from the "new" growth theory seriously (where it might be difficult in $R \& D$ based models to justify that endogenous technological progress comes along without any externalities), fluctuations go hand in hand with imperfections. This is true even in our setup where all firms operate under perfect competition, including R\&D firms. ${ }^{6}$

We will see that an economy with exogenous growth and fluctuations is a special case of our more general model. In this special case, which could be argued to reflect the standard $\mathrm{RBC}$ approach, fluctuations and efficiency are no contradiction. In the general case with endogenous long-run growth and endogenous short-run fluctuations, fluctuations and efficiency contradict each other. Here as well, a simple parameter restriction allows us to derive a very intuitive closed form expression for the value function - the standard measure of welfare.

We relate our analysis of endogenous volatility and welfare to taxation for two reasons: First, there is a considerable heterogeneity in tax systems across countries and over time (e.g. Mendoza, Tesar and Razin, 1994; Padovano and Galli, 2001). For the US, two major tax reforms, the Tax Reform Act of 1986 and the Economic Recovery Tax Act of 1981 (see e.g. Auerbach and Slemrod, 1997), took place around the point in time where the break in

\footnotetext{
${ }^{4}$ More recent work, analysing international linkages under imperfections or monetary business cycles under price staggering, include Chari, Kehoe and McGrattan (2000) or Kehoe and Perri (2002).

${ }^{5}$ Epaulart and Pommeret (2003), Krebs (2003) or Barlevy (2004) find that welfare gains from less volatility can be substantially larger and increase up to several percentage points. Lucas (2003) argues that welfare gains remain small under realistic parameter assumptions.

${ }^{6}$ There are by now various papers that stress that R\&D and perfect competition does not contradict each other. The first paper seems to be Funk (1996). Later work includes Boldrin and Levine (2004), Hellwig and Irmen (2001) and Wälde (2002).
} 
GDP volatility is usually identified (between the 4th quarter of 1982 and 3rd quarter of 1985, according to Stock and Watson, 2003). It is therefore natural to ask whether tax reforms or cross-country differences in tax systems are candidates for understanding differences in volatility. It is generally accepted that taxes can affect the growth rate of a country or its natural rate of unemployment - they could therefore also affect its natural amount of volatility. Second, the inefficiency introduced by the endogeneity of $R \& D$ and volatility can in principle be eliminated by appropriate taxes and subsidies. We do not require that the government has a lot of information about the current state of the economy and assume that it sets constant, i.e. time- and state-invariant, taxes on labour and capital income, wealth, consumption, investment and R\&D.

Talking more precisely about our results, one contribution is the derivation of analytical measures of volatility in a model characterized by "standard" properties: infinite planning horizon of the representative agent, standard intertemporal optimization decisions concerning savings and investment under risk aversion, uncertainty from properties of technological progress and perfect competition for all production processes. Analytical measures for volatility (and also welfare) can be obtained by assuming a simple parameter restriction. Analyzing the behaviour of an economy for restrictions of this type has turned out to be very useful (e.g. Long and Plosser, 1983; Xie, 1991; Benhabib and Rustichini, 1994; Wälde, 2005). This restriction allows us to represent equilibrium properties of our economy by a simple linear stochastic differential equation for instantaneous utility. Using the methods presented by Garcia and Griego (1994), we can then analytically compute moments of time series as predicted by our model. We then use the coefficient of variation as our measure of volatility.

This parameter restriction also allows us to compute an explicit expression for welfare. In doing so, we obtain a deterministic differential equation that describes how the economy evolves in an expected sense, i.e. how expected instantaneous utility evolves for $\tau>t$, where $t$ is today. This differential equation nicely shows that our economy behaves in this expected sense exactly as a deterministic Solow growth economy behaves with a fixed saving rate. Intuitively speaking, our stochastic economy turns out to be a Solow growth economy where labour productivity increases at (endogenous and optimally chosen) random points in time by discrete amounts.

Concerning the effects of taxation on volatility, we find that volatility is affected through three channels: The speed of convergence, the expected length of a cycle and the degree how strongly cyclical components are thrown back once a new technology arrives. All of these three channels can be easily related to properties of transitional paths towards some steady state. As taxes affect transitional paths of various economic variables, taxation affects volatility. For the equilibrium we analyze, taxes on labour and capital income and investment goods increase volatility, taxes on $\mathrm{R} \& \mathrm{D}$ and wealth have a stabilizing effect, a tax on consumption goods is neutral. A stabilization policy does not require knowledge about the current state of the economy. Taxes are constant and thereby time- and state-invariant. Nevertheless, higher or lower tax levels can stabilize or destabilize the economy.

Our welfare analysis shows that taxes on investment goods and R\&D directly affect the source of volatility and growth, i.e. the portfolio choice between capital accumulation and $\mathrm{R} \& \mathrm{D}$, and can therefore be used to internalize externalities. All other taxes are welfare reducing, given that they are used for some exogenous government expenditure (which, for simplicity, is modelled to have no welfare or productivity effect). When we look at the effects of taxes on volatility and welfare jointly, it turns out that stabilizing an economy is not necessarily welfare increasing. Increasing a tax on wealth or factor income reduces 
welfare, but the tax on factor income increases volatility while the tax on wealth reduces volatility. The objective of government intervention should be to internalize external effects, as in standard public finance approaches. The efficient factor allocation would then be characterized by a certain corresponding amount of volatility. The causal link from volatility to welfare in the Lucas sense is therefore opened up with endogenous volatility and implies that one can only talk of (positive or negative) correlations between volatility and welfare.

Clearly, the (in-)efficiency of fluctuations has been discussed or analyzed at least since Keynes's General Theory. In contrast to the traditional RBC approach referred to above, many authors have stressed various types of inefficiencies in the economy which arise or are amplified because of fluctuations. In the recent literature, Aghion, Banerjee and Picketty (1999), also referred to above, argue that fluctuations contain phases where "savings are underutilized in the sense of being invested in an inferior asset". More quantitatively, Gali, Gertler and Lopez (2003) compute gains from stabilization that arise because of an inefficient factor allocation and the asymmetry of changes in inefficiencies over the cycle. Greenwood and Huffman (1991) study an economy whose inefficiency stems from taxation and find that a stabilization policy that builds on information about the current state of the economy is welfare improving. None of these papers stresses the inefficiency resulting from the joint endogeneity of long-run growth and short-run fluctuations. With exogenous growth and fluctuations, fluctuations are efficient, with endogenous fluctuations, they are not.

From a more positive (and not normative) perspective, understanding and explaining the effects of fiscal policy has a long tradition as well. Greenwood and Huffman (1991) find, following a RBC-type calibration approach, that taxes on average amplify variability of macroeconomic aggregates. Jones (2002) finds in his mainly econometric analysis that fiscal policy in the US (captured by the tax rates on labour and capital income and government purchases from 1958 to 1997) has not stabilized the economy to a strong degree. Burnside, Eichenbaum and Fisher (2004) argue that increases in US government military purchases increase tax rates on capital and labour income which in turn increase aggregate hours worked and decrease real wages. They argue that the neoclassical growth model can reasonably replicate these links. Fatás and Mihov (2003) empirically analyze the link between discretionary government spending and volatility and find that "aggressive use of fiscal policy generates undesirable volatility and leads to lower economic growth". To the best of our knowledge, ours is the first paper that proposes an explicit analytical expression for volatility. This expression allows to understand the different channels through which tax policy affects volatility. As we keep taxes constant, we highlight that a volatile economy is not necessarily the result of large variations in tax rates over time but could be the result of a too high or too low level of constant tax rates. Hence, breaks over time can result from a single change of a tax rate and cross-country differences result from differences in tax levels. ${ }^{7}$

\section{The model}

The model will be presented in three parts: technologies, the government and consumers. As the technological setup of our economy is close to the one in Wälde (2005), the first part will be relatively brief. The introduction of government activities and the implications for household behavior are new and will be presented in more detail.

\footnotetext{
${ }^{7}$ From a modeling perspective, the present paper uses the model developed in Wälde (2005) and extends it for various tax rates and the government sector. The methods of Garcia and Griego (1994), on which most of our results here are based, were not used in Wälde (2005).
} 


\subsection{Technologies}

Technological progress is labour augmenting and embodied in capital. All capital goods can be identified by a number denoting their date of manufacture and therefore their vintage. A capital good $K_{j}$ of vintage $j$ allows workers to produce with a labour productivity $A^{j}$, where $A>1$ is a constant parameter. Hence, a more modern vintage $j+1$ implies a labour productivity that is $A$ times higher than labour productivity of vintage $j$. The corresponding production function reads $Y_{j}=K_{j}^{\alpha}\left(A^{j} L_{j}\right)^{1-\alpha}$, where the amount of labour allocated to that vintage is denoted by $L_{j}$ and $0<\alpha<1$ is the output elasticity of capital. The sum of labour employment $L_{j}$ per vintage equals aggregate constant labour supply, $\sum_{j=0}^{q} L_{j}=L$ where $q$ is the most advanced vintage currently available.

Independently of which vintage is used, the same type of output is produced. Aggregate output is used for producing consumption goods $C$, investment goods $I$, as an input $R$ for doing R\&D and for government expenditures $G$,

$$
C+I+R+G=Y=\Sigma_{j=0}^{q} Y_{j} .
$$

The quantities $C, I$ and $R$ stand for net resources used for these activities, i.e. after taxation. All activities in the economy take place under perfect competition. The producer prices of the production, consumption, investment and research good will therefore be identical,

$$
p_{Y}=p_{C}=p_{I}=p_{R}
$$

$\mathrm{R} \& \mathrm{D}$ is a risky activity. This is modelled by the Poisson process $q$ where the probability per unit of time $d t$ of an innovation, i.e. of successful R\&D, is given by $\lambda d t$, where $\lambda$ is the arrival rate of $q$. At the level of an individual $\mathrm{R} \& \mathrm{D}$ firm $f$, there are constant returns to scale and the firm arrival rate is $\lambda_{f}=D^{-1} h(R / D) R_{f}$, where $D$ captures the "difficulty" of doing $\mathrm{R} \& \mathrm{D}, h(\cdot)$ is an externality and $R_{f}$ are resources used by the firm. The difficulty function $D$ and the externality $h(\cdot)$ are taken as given. As firm-level Poisson processes $q_{f}$ can be added up, we obtain

$$
\lambda=\frac{R}{D} h\left(\frac{R}{D}\right)=\left(\frac{R}{D}\right)^{1-\gamma}, \quad 0<\gamma<1
$$

at the sectoral level where $h(\cdot)$ implies decreasing returns to scale.

The exogenous function $D$ captures the difficulty to make an invention. Following the arguments in Segerstrom (1998), an economy that discovered already many innovations needs to put more effort into a new innovation if this innovation is to come at the same rate $\lambda$. While the amount of innovations in the past can be measured in different ways, we simply capture it by the tax-independent current size $K_{*}^{o b s}$ of the capital stock of the economy,

$$
D \equiv D_{0} K_{*}^{o b s}, \quad D_{0}>0 .
$$

This measure of the capital stock will be defined in (12).

The objective of R\&D is to develop capital goods that yield a higher labour productivity than existing capital goods. When an innovation takes place, a first prototype of a production unit of size $\kappa$ that yields a labour productivity of $A^{q+1}$ becomes available. This distinguishes this approach from standard modeling of $R \& D$ where successful $R \& D$ is argued to lead to a blueprint only. As seems to be common in many cases (Rosenberg, 1994), only the development of a first "pioneer plant" that can be used for production characterizes success 
of research. Technically, this implies that the capital stock of vintage $q+1$ is a function of the Poisson process $q$ as well. The increment $d q$ of this process can either be 0 or 1 . As successful research means $d q=1$, we can write

$$
d K_{q+1}=\kappa d q .
$$

The size of the prototype is exogenous to the model. We keep it proportional to the taxindependent size $K_{*}^{o b s}$ of the total capital stock,

$$
\kappa \equiv \kappa_{0} K_{*}^{o b s}, \quad 0<\kappa_{0} \ll 1 .
$$

When resources are allocated to capital accumulation, the capital stock of vintage $j$ increases if investment in vintage $j$ exceeds depreciation $\delta$,

$$
d K_{j}=\left(I_{j}-\delta K_{j}\right) d t, \quad j=0, \ldots, q .
$$

In contrast to $R \& D$, this is a deterministic process as capital accumulation simply means replicating existing machines.

Allowing labour to be mobile across all vintages such that wage rates equalize, total output of the economy can be represented by a simple Cobb-Douglas production function,

$$
Y=K^{\alpha} L^{1-\alpha},
$$

where vintage specific capital stocks have been aggregated to an aggregate capital index $K$,

$$
K=K_{0}+B K_{1}+\ldots+B^{q} K_{q}=\sum_{j=0}^{q} B^{j} K_{j}, \quad B \equiv A^{\frac{1-\alpha}{\alpha}} .
$$

This index can be thought of as counting the "number of machines" of vintage 0 that would be required to produce the same output $Y$ as with the current mix of vintages.

The evolution of the capital index $K$ follows from (5) and (7) by applying the change of variable formula $(\mathrm{CVF})^{8}$ to $(9)$,

$$
d K=\left(B^{q} I-\delta K\right) d t+B^{q+1} \kappa d q .
$$

The capital index increases continuously as a function of effective investment $B^{q} I$ minus depreciation. When an innovation takes place, the capital index increases by $B^{q+1} \kappa$.

\subsection{Government}

The government can levy taxes on capital $\left(\tau_{K}\right)$ and labour income $\left(\tau_{L}\right)$, wealth $\left(\tau_{W}\right)$, consumption expenditure $\left(\tau_{C}\right)$, investment $\left(\tau_{I}\right)$ and R\&D expenditure $\left(\tau_{R}\right)$. A positive tax implies a real decrease in income or an increase in the effective price (consumer price), whereas a negative tax is a subsidy. The government uses taxation to provide basic government services $G$ like rule of law. In order to focus on the effects of taxation from government expenditures, we assume that government expenditure does not affect household utility or production possibilities of the economy.

\footnotetext{
${ }^{8}$ In models with Brownian motion as a source of uncertainty, the "rules" for computing differentials are based on Ito's Lemma. The expression Ito's Lemma is inappropriate in the presence of Poisson processes and the differentials are obtained from a change of variable formula. See e.g. Garcia and Griego (1994) and Sennewald (2005) for a rigorous background and Sennewald and Wälde (2005) for an introduction.
} 
As argued in (2), producer prices are identical for all three production processes. When consumption and investment goods $C$ and $I$ or research services $R$ are sold, they are taxed differently such that consumer prices are $\left(1+\tau_{C}\right) p_{C},\left(1+\tau_{I}\right) p_{I},\left(1+\tau_{R}\right) p_{R}$. In order to rule out arbitrage between different types of goods, we assume that once a unit of production is assigned for a special purpose, it is useless for other purposes: once a consumption good is acquired, it cannot be used for e.g. investment purposes.

Taxes that increase the producer price have no theoretical upper bound. A $300 \%$ tax on the consumption good would imply that $3 / 4$ of the price are taxes going to the state and $1 / 4$ goes to the producer. Their lower bound is clearly $-100 \%$, where a good would be for free for the purchaser. The upper bound for taxes on income is 100\% (instant confiscation of income), while there is no lower bound. Hence, $-1<\tau_{C}, \tau_{I}, \tau_{R}$ and $\tau_{L}, \tau_{K}, \tau_{W}<1$.

Our capital stock index $K$ in (9) measures the size of the capital stock in units of vintage 0 . Measured in units of vintage $q$, its size is $B^{-q} K$. This is also the value of the entire capital stock in pre-tax units of the consumption good, as the relative pre-tax prices are unity from (2). Measuring wealth in after-tax prices, i.e. in "purchasing power" terms, the price of the capital good increases by the $\operatorname{tax} \tau_{I}$ and the price to be paid for one unit of the consumption good increases by $\tau_{C}$. Hence, total wealth in the economy is given by

$$
K^{o b s}=L a=\frac{1+\tau_{I}}{1+\tau_{C}} B^{-q} K,
$$

where $a$ is wealth of the representative household. The tax-independent measure of the capital stock, used in (4) and (6), can then be defined by

$$
K_{*}^{o b s} \equiv \frac{1+\tau_{C}}{1+\tau_{I}} K^{o b s}
$$

\subsection{Households}

The economy is populated by a discrete finite number of sufficiently small representative households. They maximize expected utility $U(t)$, given by the "sum" of instantaneous utilities $u(\cdot)$ resulting from consumption flows $c(\tau)$, discounted at the rate of time preference $\rho$,

$$
U(t)=E_{t} \int_{t}^{\infty} e^{-\rho[\tau-t]} u(c(\tau)) d \tau
$$

where the instantaneous utility function $u(\cdot)$ is characterized by constant relative risk aversion, ${ }^{9}$

$$
u(c(\tau))=\frac{c(\tau)^{1-\sigma}}{1-\sigma}, \quad \sigma>0 .
$$

The budget constraint reflects investment possibilities in this economy and the impact of tax policy and shows how wealth $a$ evolves over time. Households can invest in a risky asset by financing $R \& D$ and in an (instantaneously) riskless asset by accumulating capital. We measure wealth in units of the consumption good, priced at consumer prices. The budget

\footnotetext{
${ }^{9}$ For analytical convenience and readability, we neglect the term $-(1-\sigma)^{-1}$, which is sometimes included in the instantaneous utility function.
} 
constraint can intuitively best be understood by starting from (A.13) in the appendix,

$$
\begin{aligned}
d a & =\left(\frac{\left(1-\tau_{K}\right) \sum_{j=0}^{q+1} w_{j}^{K} k_{j}}{\left(1+\tau_{C}\right) p_{C}}+\frac{1-\tau_{L}}{1+\tau_{C}} \frac{w}{p_{C}}-c-\frac{1+\tau_{R}}{1+\tau_{C}} i\right) d t \\
& -\left(\frac{1-\tau_{K}}{1+\tau_{I}} \delta+\tau_{W}\right) a d t+\left(\frac{1+\tau_{I}}{1+\tau_{C}} \kappa \frac{i}{R}-\frac{B-1}{B} a\right) d q .
\end{aligned}
$$

Nominal gross capital income $\sum_{j=0}^{q+1} w_{j}^{K} k_{j}$ from all vintages $j$ is taxed at $\tau_{K}$, yielding net capital income. Dividing by the consumer price $\left(1+\tau_{C}\right) p_{C}$ of the consumption good gives real net capital income in units of the consumption good. The same reasoning applies to labour income $w$, consumption $c$ and investment $i$ into $\mathrm{R} \& \mathrm{D}$. The expression on the first line therefore captures the increase in wealth $a$, measured in units of the consumption good at consumer prices. The first expression on the second line captures the wealth-reducing effect of the after-tax depreciation rate and of the tax on wealth. The tax rates $\tau_{K}$ and $\tau_{I}$ in front of the depreciation rate ensure that taxes are partly refunded i.e. only net (and not gross) investment will be taxed (cf. eqs. (A.14) and (A.2)). The second expression increases an individual's wealth in case of successful research by the "dividend payments" minus an economic depreciation term. Dividend payments at the household level are given by the share $i / R$ of the successful research project the household financed times total dividend payments $\frac{1+\tau_{I}}{1+\tau_{C}} \kappa$. Dividend payments are determined by the size $\kappa$ of the prototype times its aftertax price $\left(1+\tau_{I}\right) /\left(1+\tau_{C}\right)$ in units of the consumption good. ${ }^{10}$ The term $1+\tau_{I}$ implies that research yields not only a capital good (which would have a value of $p_{I}$ ) but already an installed capital good (whose value is $\left.\left(1+\tau_{I}\right) p_{I}\right)$. Economic depreciation $(B-1) / B$ results from the vintage capital structure as the most advanced capital good has a relative price of unity (cf. (2)) and all other vintages then lose in value relative to the consumption good.

After some further steps (especially the pricing equations for $v_{j}$ ), and using the notation for values after taxation, the budget constraint simplifies to

$$
d a=\left(r^{*} a+w^{*}-i^{*}-c\right) d t+\left(\kappa^{*} \frac{i}{R}-s a\right) d q
$$

where $i^{*} \equiv \frac{1+\tau_{R}}{1+\tau_{C}} i, \kappa^{*} \equiv \frac{1+\tau_{I}}{1+\tau_{C}} \kappa, s \equiv \frac{B-1}{B}$ and factor rewards are

$$
r^{*} \equiv \frac{1-\tau_{K}}{1+\tau_{I}} r-\tau_{W}, \quad w^{*} \equiv \frac{1-\tau_{L}}{1+\tau_{C}} \frac{w}{p_{C}}, \quad r=B^{q} \frac{\partial Y}{\partial K}-\delta, \quad w=p_{Y} \frac{\partial Y}{\partial L}
$$

\section{Endogenous cyclical growth}

\subsection{Equilibrium}

Solving the model requires first order conditions for households for consumption and R\&D expenditure. These two conditions, together with the aggregate capital accumulation constraint (10), the goods market equilibrium (1), optimality conditions of perfectly competitive firms and a certain taxation policy fixing $G$ provides a system consisting of 7 equations that determines, given initial conditions, the time paths of $K, C, R, Y, T, w$ and $r$.

\footnotetext{
${ }^{10}$ We use the term dividend payments in a narrow sense, i.e. only for payments from successful R\&D. Data on dividend payments would also include part of factor rewards $r$ for capital.
} 
Such a system can best be understood by introducing auxiliary variables that are similarly used in many other models as well: In the classic Solow growth model, capital per effective worker $K /(A L)$ is shown to converge to a steady state and the analysis of e.g. convergence can be separated from the analysis of long-run growth. In the present context, we define $\hat{K}(\tau)$ and $\hat{C}(\tau)$ as

$$
\hat{K}(t) \equiv K(t) / A^{q(t) / \alpha}, \quad \hat{C}(t) \equiv C(t) / A^{q(t)}
$$

which is almost identical to capital and consumption per effective worker as labor supply is constant here. These variables also allow us to separate the analysis of cyclical properties of the model from long-run growth. Most of the time, we will call $\hat{K}(\tau)$ and $\hat{C}(\tau)$ cyclical components of $K(t)$ and $C(t)$, as $A^{q(t) / \alpha}$ and $A^{q(t)}$ will turn out to be the stochastic trend in our economy.

"Detrending" in (17) is undertaken by dividing by measures of the current technology level that differs between capital and consumption. This is due to the fact that $K(t)$ is a capital index and not capital expressed in units of the consumption good. Capital measured in units of the consumption good would be detrended by $A^{q(t)}$ as well. When detrending other endogenous variables by $A^{q(t)}$ as well, these detrended variables turn out to be stationary and within a bounded range. Equilibrium properties can therefore best be illustrated by studying an equilibrium in cyclical components which consists of a system in 7 equations and 7 cyclical components as well.

\subsection{An explicit solution}

It would be interesting to analyze such a system in all generality. One would run the risk, however, of losing the big picture and rather be overwhelmed by many small results. We therefore restrict ourselves to a particular parameter set of the model that allows very sharp analytical results.

Theorem 1 If the preference parameter $\sigma$ of the utility function satisfies the relationship

$$
\sigma=\frac{\left(1-\tau_{K}\right) \alpha}{1-\tau_{L}-\left(\tau_{K}-\tau_{L}\right) \alpha}
$$

we obtain a linear solution for consumption and research

$$
\hat{C}=\Psi \hat{K}, \quad \hat{R}=\Gamma \hat{K},
$$

where $\Psi$ and $\Gamma$ denote constant parameters given by

$$
\begin{gathered}
\Psi=\frac{1+\tau_{I}}{1+\tau_{C}}\left(\frac{\rho+\lambda\left(1-(1-s) \xi^{-\sigma}\right)}{\sigma}+\frac{1-\sigma}{\sigma}\left(\frac{1-\tau_{K}}{1+\tau_{I}} \delta+\tau_{W}\right)-\frac{1+\tau_{R}}{1+\tau_{I}} \Gamma\right), \\
\Gamma=\left(\frac{1+\tau_{I}}{1+\tau_{R}} \frac{\kappa_{0}}{D_{0}} \xi^{-\sigma}\right)^{\frac{1}{\gamma}} D_{0} .
\end{gathered}
$$

The arrival rate is then constant and given by

$$
\lambda=\left(\frac{1+\tau_{I}}{1+\tau_{R}} \frac{\kappa_{0}}{D_{0}} \xi^{-\sigma}\right)^{\frac{1-\gamma}{\gamma}}
$$

where we defined

$$
\xi \equiv 1-s+\kappa_{0}
$$


Proof. App. B.1.4.

Parameter restrictions as in (18) have proven useful to derive equilibrium properties which otherwise would not be easily visible (e.g. Long and Plosser, 1983; Xie, 1991; Benhabib and Rustichini, 1994; Wälde, 2005). What is peculiar about this condition is that a change in the tax rate $\tau_{L}$ or $\tau_{K}$ would at constant $\alpha$ require a change in $\sigma$ for the closed form solution to prevail. As a change in preference or technology parameters following a change in policy is not convincing, we will restrict our policy analyses to identical income tax rates, i.e. $\tau_{L}=\tau_{K} \equiv \tau_{F}$. This simplifies (18) to ${ }^{11}$

$$
\sigma=\alpha .
$$

We will assume in what follows that $\xi<1$ in (23), i.e. economic depreciation $s$ due to the innovation is larger than the relative size of dividend payments $\kappa_{0}$.

\subsection{Cyclical growth}

Exploiting the implications of theorem 1 fully, we can summarize general-equilibrium behaviour of agents in a way as simple as e.g. in the Solow growth model with exogenous growth and a constant saving rate, even though we have forward-looking agents and an uncertain environment. In terms of cyclical components, our economy follows (19) and (app. B.1.3)

$$
\begin{aligned}
d \hat{K} & =(\hat{Y}-\hat{R}-\delta \hat{K}-\hat{C}-\hat{G}) d t-\left(1-A^{-1} \xi\right) \hat{K} d q \\
& =\left(\frac{b_{0}}{\Psi^{1-\sigma}} \hat{K}^{\alpha} L^{1-\alpha}-\frac{b_{1}}{1-\sigma} \hat{K}\right) d t-\left(1-A^{-1} \xi\right) \hat{K} d q
\end{aligned}
$$

where with $\Psi$ and $\Gamma$ from (20) and (A.36),

$$
\begin{aligned}
b_{0} & \equiv \frac{1-\tau_{F}}{1+\tau_{I}} \Psi^{1-\sigma}, \\
b_{1} & \equiv(1-\sigma)\left(\frac{1+\tau_{C}}{1+\tau_{I}} \Psi+\frac{1+\tau_{R}}{1+\tau_{I}} \Gamma+\frac{1-\tau_{K}}{1+\tau_{I}} \delta+\tau_{W}\right) \\
& =\frac{1-\sigma}{\sigma}\left(\rho+\lambda\left[1-(1-s) \xi^{-\sigma}\right]+\frac{1-\tau_{K}}{1+\tau_{I}} \delta+\tau_{W}\right) .
\end{aligned}
$$

The differential equation (25) is the capital accumulation constraint (10), expressed for cyclical components and satisfying utility-maximizing behaviour of agents. Inserting (19) and some further steps (app. B.2.1) give the one-dimensional stochastic differential equation (26) in $\hat{K}$.

Note that the expressions containing parameters $b_{0}$ and $b_{1}$ have an economic meaning: the first term represents cyclical output of this economy, reduced by taxation. This is visible from $\hat{Y}=\hat{K}^{\alpha} L^{1-\alpha}$ (app. B.1.3). The $b_{1}$ term represents resource allocation to R\&D and consumption, in addition to physical capital depreciation, all corrected for taxation. As (26) shows, $b_{1}$ also captures the speed of convergence of $\hat{K}$ relative to its steady state. The

\footnotetext{
${ }^{11}$ The parameter restriction $\sigma=\alpha$ implies a relatively high intertemporal elasticity of substitution $\sigma^{-1}$ of above unity. Wether the intertemporal elasticity of substitution implied by this restriction is plausible or not (for a discussion, see Wälde, 2005), the relevance of our results depends only on whether one believes that changes in $\sigma$ will fundamentally change our insights. As will turn out further below, this is not the case.
} 
differential equation (26) is illustrated in the following figure.

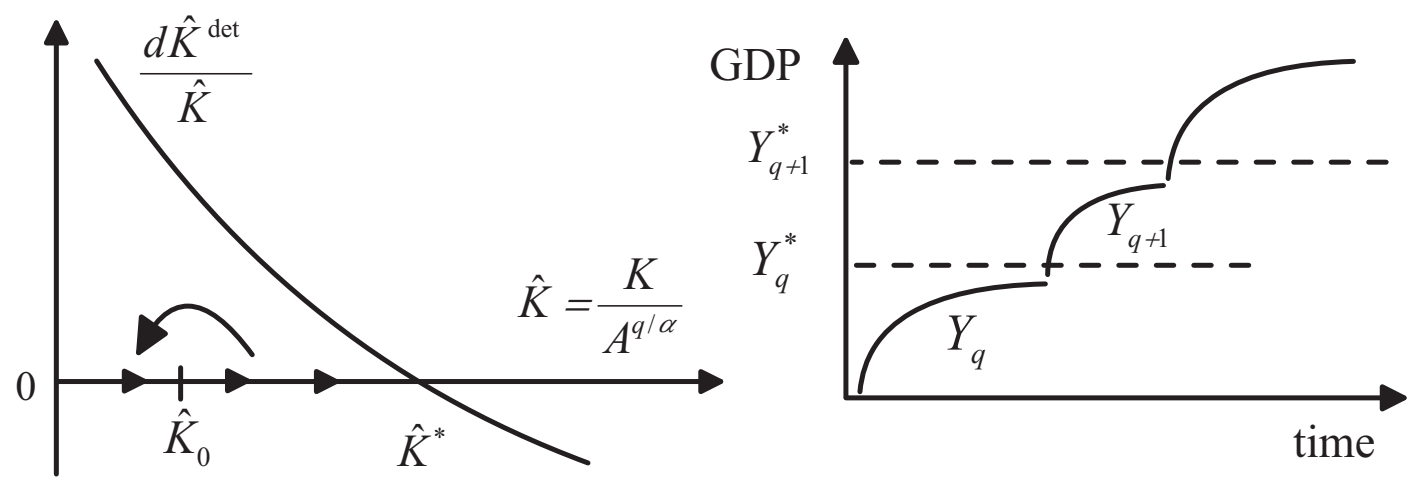

Figure 1: General equilibrium dynamics of the capital stock per effective worker and GDP growth cycles

The figure on the left plots $\hat{K}$ on the horizontal axis and the proportional (deterministic part of the) change $d \hat{K} / \hat{K}$ on the vertical one. The steady state $\hat{K}^{*}$ to which the economy approaches without any jumps in technology is from (26) and (27)

$$
\hat{K}^{*}=\left(\frac{1-\tau_{F}}{1+\tau_{I}} \frac{1-\sigma}{b_{1}}\right)^{\frac{1}{1-\alpha}} L=\left(\frac{1-\tau_{F}}{1+\tau_{I}} \frac{\sigma}{\rho+\lambda\left[1-(1-s) \xi^{-\sigma}\right]+\frac{1-\tau_{K}}{1+\tau_{I}} \delta+\tau_{W}}\right)^{\frac{1}{1-\alpha}} L,
$$

where we used (28) for the second equality.

We can now start our analysis as we do in deterministic models. Assume an initial capital stock $\hat{K}_{0}$. Agents invest part of their savings in R\&D, the rest goes to capital accumulation. Assuming a certain length of time without jumps, i.e. without successful innovation, the economy grows due to more capital and converges to the steady state $\hat{K}^{*}$. As in the Solow model, growth is initially high and approaches zero. Once a jump occurs and $q$ increases by 1 , the capital stock of the economy increases by the size $\kappa$ of the prototype from (5). If the capital stock $K$ remained unchanged, capital per effective worker $\hat{K}(\tau)$ from $(17)$ would decreases by a discrete amount as the frontier technology increases by the discrete amount $A$. When we assume that the size of the new machine is sufficiently small relative to the technological improvement, $A^{-1} \xi<1$ (which is the only empirically plausible assumption and which also follows from our assumption after (23)), the cyclical component $\hat{K}(\tau)$ falls due to an innovation, i.e. the economy is thrown back towards the origin in fig. 1 . With a lower capital stock per effective worker, investment in capital accumulation becomes more profitable as the marginal productivity of capital is higher. Growth rates jump to a higher level and approach zero again unless a new innovation takes place.

The discrete increases of labour productivity by $A$ imply a step function in TFP - in contrast to the smooth increase in TFP in balanced growth models. The implied evolution of GDP is shown in the right panel of fig. 1. Fluctuations are natural in a growing economy. 


\section{Measuring welfare and volatility}

\subsection{The value function}

Our measure of welfare is the value function which, by definition, is $V(t) \equiv \max _{\{c(\tau), i(\tau)\}}$ $E_{t} \int_{t}^{\infty} e^{-\rho[\tau-t]} u(c(\tau)) d \tau$. Pulling the expectations operator into the integral gives

$$
V(t)=\max _{\{c(\tau), i(\tau)\}} \int_{t}^{\infty} e^{-\rho[\tau-t]} E_{t} u(c(\tau)) d \tau .
$$

Obviously, the value of the optimal program depends on the evolution of expected instantaneous utility, $E_{t} u(c(\tau)){ }^{12}$

\subsubsection{Evolution of expected instantaneous utility}

Let us now analyze how expected instantaneous utility,

$$
m_{1}(\tau) \equiv E_{t} u(c(\tau))
$$

evolves. For notational simplicity, we denote

$$
\Theta \equiv A^{1-\sigma}, \quad \Xi=\xi^{1-\sigma} .
$$

Computing expected quantities as in (31) can be done in two ways. Either, a stochastic differential equation is expressed in its integral version, expectations operators are applied and the resulting deterministic differential equation is solved. Or, the stochastic differential equation is solved directly and then expectation operators are applied. The background for either approach is in Garcia and Griego (1994). We follow the first way here.

The evolution of $u(c(\tau))$, denoted by $u(t)$ for simplicity, is described by the differential equation (app. C.1.1),

$$
d u(t)=\left(b_{0} \Theta^{q(t)}-b_{1} u(t)\right) d t-b_{2} u(t) d q(t),
$$

where $b_{0}$ and $b_{1}$ are as in (27) and (28) and

$$
b_{2} \equiv 1-\Xi
$$

can be understood as a measure of the "novelty" of a new technology. When $A$ is high, $b_{2}$ is high as well as a high degree of novelty increases $b_{2}$ through high economic depreciation $s$, defined before (16). Note that we assume $b_{2}>0$ which holds due to the plausibility assumption of $\xi<1$ made after (23). This differential equation shows that $u(t)$ behaves similarly to $\hat{K}$ illustrated in fig. 1 . Starting from some $u_{0}, u(t)$ moves towards the current steady state $b_{0} \Theta^{q(t)} / b_{1}$ as long as no technology jump takes place, i.e. as long as $d q=0$. When $q$ jumps, $u(t)$ reduces by a small amount as agents postpone consumption ${ }^{13}$ and as a fraction

\footnotetext{
${ }^{12}$ The integral and the expectations operator can be exchanged when, under a technical condition, both the expected integral, i.e. our objective function (13), and the integral of the expected expression exist. The expected integral exists by assumption as otherwise the maximization problem of the household would be meaningless. The existence of the integral of the expected expression will be shown by computing it. The existence proof is therefore an ex-post proof. We are grateful to Ken Sennewald for discussions of this issue.

${ }^{13}$ This is due to $\sigma=\alpha$ and the implied intertemporal elasticity of substitution. Under an alternative condition and closed form solution, consumption would not decrease (Wälde, 2005, footnote 20). The behavior of the utility level after a technological jump is not important for subsequent results. The $\sigma=\alpha$ assumption would also matter for the link between growth and uncertainty (cf. e.g. de Hek 1999).
} 
of their wealth depreciates economically. The difference to $\hat{K}$ consists in the behaviour of the current steady state. As $u(t)$ is the level of utility and not its cyclical component or utility per representative worker, the steady state moves to the right with each new technology. After an innovation and the subsequent reduction in $u(t)$, instantaneous utility approaches this new steady state until the next jump occurs - similar to GDP in fig. 1.

Given this stochastic differential equation and forming expectations about $u(\tau)$ for $\tau>t$ leads to a deterministic ordinary differential equation in $m_{1}(\tau)$. Computing a solution for this ODE is possible as its non-linearity can be removed by a variable transformation similar to the approach for the deterministic Solow growth model (e.g. Barro and Sala-i-Martin, 1995, p. 53). Defining $g$ as the growth rate and $\beta$ as the convergence rate of expected utility $m_{1}(\tau)$ (and keeping the difference to $b_{1}$ in $(28)$, the speed of convergence of $\hat{K}$, in mind),

$$
\begin{aligned}
& g \equiv(\Theta-1) \lambda, \\
& \beta \equiv g+b_{1}+b_{2} \lambda=b_{1}+\lambda[\Theta-\Xi]
\end{aligned}
$$

respectively, we obtain (app. 7.1) an explicit expression for (31),

$$
m_{1}(\tau)=e^{-(\beta-g)(\tau-t)}(u(t)-\mu)+e^{g[\tau-t]} \mu,
$$

where

$$
\mu \equiv \Theta^{q(t)} b_{0} / \beta
$$

The second term of this equation, $e^{g[\tau-t]} \mu$, says that expected utility, starting in $t$ where $q(t)$ and $K(t)$ and thereby $u(t)$ are given as initial conditions, grows exponentially at the innovation rate $g$. From (35), the innovation rate is basically driven by the arrival rate $\lambda$. In the long run, $g$ is the average growth rate of instantaneous utility. The first term says that $u(t)$ converges to $\mu$ at the convergence rate $\beta$. The term $\mu$ is the expected value, today in $t$, of instantaneous utility in $\tau \rightarrow \infty$, when instantaneous utility is deterministically detrended. This follows immediately from rewriting (37) as $e^{-g[\tau-t]} m_{1}(\tau)=e^{-\beta[\tau-t]}(u(t)-\mu)+\mu .^{14}$ Somewhat imprecisely but nevertheless useful, $\mu$ could be called "average instantaneous utility".

Apart from showing growth of expected quantities in our setup, equation (37) illustrates the similarity of the evolution of expected quantities in this setup to the evolution of quantities in the Solow growth model. When we replace $\mu$ by the Solow steady state utility level, the expected evolution here is identical to the certain evolution in Solow's model (where $g$ and $\beta$ would then stand for the growth and convergence rate in the Solow sense). In contrast to Solow, the role played by short-run convergence is ambiguous: while in the Solow model one usually assumes a capital stock that lies to the left of the steady state and convergence implies higher average growth rates between today and some future point in time $\tau$, the capital stock here (and the implied consumption and utility level) will in $50 \%$ of all realizations lie to the right of the mean $\mu$. Convergence then implies lower average growth rates.

\footnotetext{
${ }^{14}$ Obviously, detrending is possible in at least two ways here: The "stochastic detrending" in (17) looks at past realizations of $q(t)$ and removes the stochastic trend $A^{q(t) / \alpha}$ or $A^{q(t)}$ of some stochastic trended variable $X(t)$. "Deterministic detrending" removes an expected growth trend by dividing expected expressions by its growth component $e^{g[\tau-t]}$. In either case, by definition, the resulting cyclical component has a finite constant long-run mean. Stochastic detrending also implies finite and constant higher long-run moments (app. 7.3), which, however, is not necessarily the case for deterministic detrending (app. 7.2).
} 


\subsubsection{Computing the value function}

We can now insert the expression for utility under optimal behaviour from (37) into (30) and get, after computing deterministic integrals (app. C.1.2),

$$
V(t)=\frac{\mu}{\rho-g}-\frac{\mu-u(t)}{\rho-g+\beta}
$$

The derivation assumed $\rho>g$ which makes the integral in (13) bounded. ${ }^{15}$ While in deterministic models the growth rate of utility must not be larger than the time preference rate, in this stochastic model, the boundedness condition requires that the growth rate of expected instantaneous utility must not exceed the time preference rate.

The value function can best be understood by going back to equation (37): The value to which the expected value of deterministically detrended utility converges is $\mu$. This value appears in $(39)$ as $\mu /(\rho-g)$, i.e. the present value of utility that amounts to $\mu$ today, grows at rate $g$ and where the discount factor is $\rho$. In addition, welfare today depends on a convergence term. If utility today is lower than $\mu$, there will be convergence towards this long-run mean and utility will be lower compared to a situation where $u(t)$ equals or exceeds $\mu$. However, the difference $\mu-u(t)$ is not as important as $\mu$ in the other term, as this effect is transitory. Hence, the present value of the convergence process is computed subject to the convergence rate $\beta$.

Note that an identical expression for the value function would result in an analysis of the Solow model. The only difference would consist in the meaning of $\mu$. While here, $\mu$ stands for "average instantaneous utility", it would stand for steady state utility in Solow's model.

Summarizing, the value of the optimal program $V(t)$ basically depends on four crucial determinants: "average instantaneous utility" $\mu$, utility today $u(t)$, the innovation rate $g$ and the convergence coefficient $\beta$. Studying welfare effects of taxation can therefore be broken down into effects on these four elements that determine the value function.

\subsection{The cyclical component}

While the measure for welfare was straightforward, there is an almost infinite number of possible measures of volatility. The empirically oriented literature provides two examples: The variance of growth rates (e.g. of GDP) and the variance of cyclical components. App. 7.2 analyses the variance of the growth rate of instantaneous utility $u$ in detail. It turns out that the resulting expression and therefore variances of all other time-series like e.g. GDP, do not lend themselves to a straightforward analysis. This is due to two facts. First, growth rates for long time horizons, i.e. for $\tau \rightarrow \infty$, do approach a constant mean but do not have finite variance or finite higher moments. Second, while annual growth rates have finite moments, they are extremely complex (cf. equ. (52)) and a comparative static analysis is close to intractable. We therefore use cyclical components as our basic random variable to measure volatility.

\subsubsection{The evolution of the cyclical component}

Cyclical components of time series can be defined and therefore computed in many ways and the literature offers a large number of filters. None of these filters, given their computational complexity, would allow us to derive cyclical components that would yield an explicit

\footnotetext{
${ }^{15}$ Hence, the integral of the expected expression exists. See footnote 12.
} 
analytical expression for volatility. We therefore use a very simple filter, the Solow-type detrending rule used in (17), to compute our cyclical components. Usual filters, think of the Hodrick-Prescott filter, detrend by removing a smooth trend from a time series. Our filter captures the trend by a step function $A^{q(t)}$, caused by the discrete increases of $q(t)$. In spirit, however, these filters are very close as both remove past realizations of growth processes to obtain the cyclical components.

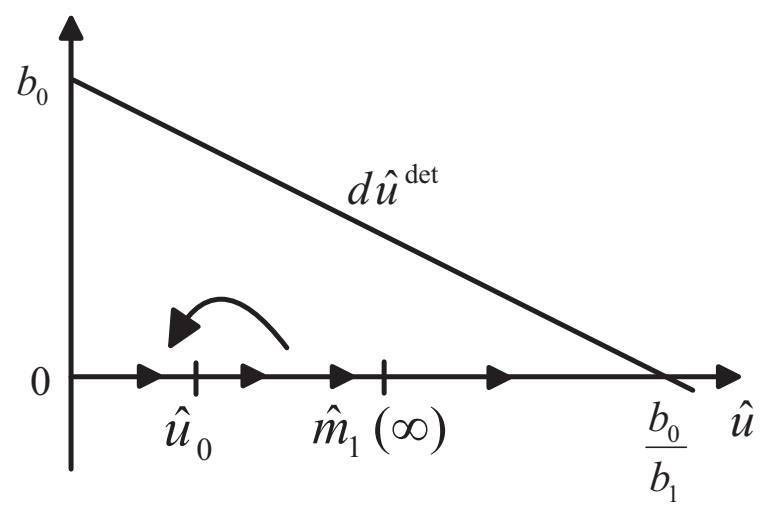

Figure 2: Detrended utility

In order to understand the detrending method proposed here, we look at the evolution of detrended utility. ${ }^{16}$ We define detrended individual utility, in analogy to (14), as the component of utility that stems from the cyclical component of consumption in (17),

$$
\hat{u}=\frac{(\hat{C} / L)^{1-\sigma}}{1-\sigma}
$$

With

$$
\hat{b}_{2} \equiv 1-\Xi / \Theta
$$

detrended utility follows (app. 7.3)

$$
d \hat{u}(t)=\left(b_{0}-b_{1} \hat{u}(t)\right) d t-\hat{b}_{2} \hat{u}(t) d q(t) .
$$

This law of motion is basically identical to (33), only that the $\Theta^{q(t)}$ term is missing and $\hat{b}_{2}$ slightly differs from $b_{2}$. Again, we can gain an intuitive understanding by plotting in fig. 2 the deterministic part $\left(b_{0}-b_{1} \hat{u}(t)\right)$ with $\hat{u}(t)$ on the horizontal axis.

Obviously, the cyclical component of utility has a range between 0 and $b_{0} / b_{1}$, provided that $\hat{u}_{0}$ lies within this range. Starting from $\hat{u}_{0}$ and as long as no innovation takes place, the cyclical component approaches its upper bound. Each innovation reduces $\hat{u}(t)$ to $\left(1-\hat{b}_{2}\right) \hat{u}(t)$, i.e. $\Xi / \Theta$ percent of its level before the innovation. As the reduction is proportional, $\hat{u}(t)$ is always positive.

\footnotetext{
${ }^{16}$ In Lucas-type approaches, the measure of volatility is based on the evolution of consumption. For analytical tractability, we need to work with detrended utility. There are approximation rules, however, which allow to compute e.g. the coefficient of variation of consumption once the coefficient of variation of utility (a monotone transformation of consumption) is known (cf. e.g. Rinne, 1997).
} 


\subsubsection{The coefficient of variation}

Exploiting again the methods in Garcia and Griego (1994), we can compute moments of this cyclical component. This follows similar step as above for (37). In fact, denoting the $i$ th moment, in analogy to (31), by

$$
\hat{m}_{i}(\tau) \equiv E_{t} \hat{u}(\tau)^{i},
$$

the first and second moment are given in the long run by (app. 7.3.2 $)^{17}$

$$
\begin{aligned}
& \hat{m}_{1}(\infty)=\frac{b_{0}}{b_{1}+\lambda \hat{b}_{2}}, \\
& \hat{m}_{2}(\infty)=\frac{2 b_{0}}{2 b_{1}+\lambda\left[1-\left(1-\hat{b}_{2}\right)^{2}\right]} \hat{m}_{1}(\infty) .
\end{aligned}
$$

Using these moments, computing the variance would be straightforward. As a measure of volatility, the variance seems less suitable in our context, however, as it is scale dependent. We therefore prefer the coefficient of variation $(c v)$. Given that the variance of a random variable is the difference between its second moment and the square of its mean, we obtain

$$
c v^{2} \equiv \frac{\lim _{\tau \rightarrow \infty} \operatorname{var}_{t} \hat{u}(\tau)}{\left(\lim _{\tau \rightarrow \infty} E_{t} \hat{u}(\tau)\right)^{2}}=\frac{\hat{m}_{2}(\infty)}{\left(\hat{m}_{1}(\infty)\right)^{2}}-1 .
$$

When computing the second moment in all generality, an expression similarly complex as for the variance of the growth rate, presented in the appendix in (52) appears. When we focus on the long run where the convergence of the initial value $\hat{u}_{0}$ to $\hat{m}_{1}(\infty)$ in (42) is ignored, however, this measure simplifies. This would be the case for the variance of growth rates as well, see (53). Studying the long run with this measure of volatility is not at all as problematic as using growth rates, however. In the latter case, we analyze the variance of multi-annual growth rates. Those could never be observed. In the former case, looking at the long run simply means studying the volatility of some stationary long-run distribution. This corresponds to studying the variance of the cyclical component of a time series that is very long. This being said, our $c v$ is (app. C.3.2)

$$
c v^{2}=\frac{\hat{b}_{2}^{2}}{2 b_{1} / \lambda+1-\left(1-\hat{b}_{2}\right)^{2}} .
$$

To obtain a feeling for this measure, we go back to fig. 2. The first moment $\hat{m}_{1}(\infty)$ lies between 0 and the steady state $b_{0} / b_{1}$. This is intuitively clear, given the permanent convergence towards $b_{0} / b_{1}$ and the occasional being thrown back. As the process $\hat{u}(t)$ is completely described by (42), given an arrival rate $\lambda$, only the parameters of this process, $b_{0}, b_{1}, \hat{b}_{2}$ and $\lambda$, can show up in its moments. A larger $b_{0}$ and a smaller $b_{1}$ shifts the mean $\hat{m}_{1}(\infty)$ to the right; this is clear from fig. 2 as a larger $b_{0}$ and a smaller $b_{1}$ shift the $d \hat{u}$ line to the right. When $\hat{b}_{2}$ or $\lambda$ increase, the mean shifts to the left as either jumps to the left are larger or more frequent.

The second moment has the same properties as the first moment $\hat{m}_{1}(\infty)$ with respect to $b_{0}, b_{1}$ and $\lambda$, as can be directly seen in (45). As the term $1-\left(1-\hat{b}_{2}\right)^{2}$ increases in $\hat{b}_{2}$, it

\footnotetext{
${ }^{17}$ The structure of the moments is remarkable as it shows that the distribution of $\hat{u}$ exists, is unique and represents a generalization of the $\beta$-distribution. We are grateful to Christian Kleiber for pointing this out to us. For more discussion see app. 7.3.2.
} 
also behaves as $\hat{m}_{1}(\infty)$ with respect to $\hat{b}_{2}$, i.e. it decreases in $\hat{b}_{2}$. Simply speaking, a larger range and more frequent jumps increase the second moment, a measure of dispersion.

Computing the $c v$ then shows that it is independent of $b_{0}$. This is not surprising as $b_{0}$ is a scaling parameter and the $c v$ is by construction scale independent. This can intuitively also be understood from fig. 2 where the effect of $b_{0}$ on the cyclical component could be removed by scaling both axes with $1 / b_{0}$. The effect of other parameters will be discussed below.

\subsubsection{Random walks and stationary cyclical components}

Following the work of Nelson and Plosser (1982), the majority view seems to be now that most observed macroeconomic time series exhibit difference-stationarity rather than trendstationarity. ${ }^{18}$ This implies that theoretical models should predict difference stationary time paths as well, i.e. trends and cyclical components should both be stochastic as opposed to models where only cyclical components are stochastic and the trend is deterministic. An example of the latter type is given by King and Rebelo (1999), where the technology is $Y_{t}=A_{t} K_{t}^{\alpha}\left[N_{t} X_{t}\right]^{1-\alpha}$, labour productivity increases according to $X_{t+1}=\gamma X_{t}$ with $\gamma>1$ and TFP follows $A_{t}=A_{t-1}^{\rho} e^{\varepsilon_{t}}$ with $\rho<1$ and $\varepsilon_{t}$ being normally iid. Models of the former type are presented e.g. by King, Plosser, Stock and Watson (1991) where the log of TFP is assumed to follow a exogenously given random walk with drift. Models with endogenous stochastic trends include King, Plosser and Rebelo (1988, sect. 3.3), Fatás (2000) or Barlevy (2004). Sources of fluctuations are exogenous in these models.

We now show that our model exhibits indeed a stochastic trend and stochastic stationary cyclical components. The crucial difference to models just cited is of course the endogeneity of shocks to TFP. How often shocks occur, i.e. how often the technology jumps, depends on decisions made by investors. ${ }^{19}$ The well-known Aghion-Howitt (1992) random technological progress specification can therefore also endogenously account, once properly included in a model of growth and fluctuations, for business cycle properties so far replicated only in an exogenous way.

We can write $(17)$ as $\ln K(t)=q(t)(\ln A) / \alpha+\ln \hat{K}(t)$, i.e. we split our time series $\ln K(t)$ into a trend component $q(t)(\ln A) / \alpha$ and into a stationary cyclical component $\ln \hat{K}(t)$, in the sense of Beveridge and Nelson (1981). Both the trend component and the stationary component are stochastic. Even though we are in continuous time, we can easily relate our trend component to a discrete time random walk as we can describe it by the pure random walk with drift: $q(t)=q(t-1)+\lambda+\varepsilon(t)$, where $\varepsilon(t) \sim(0, \lambda){ }^{20}$ Hence, our trend component has a unit root and our cyclical component $\hat{K}(t)$ is stationary as just shown for $\hat{u}$.

\footnotetext{
${ }^{18}$ More recent work on stationarity includes Bai and Ng (2004).

${ }^{19}$ Other models of endogenous fluctuations and growth, all cited in the introduction, are of a deterministic nature. The only exception is Bental and Peled (1996) who were the first to study endogenous fluctuations and growth. Unfortunately, their model is fairly complex which makes an explicit analysis of stochastic properties of trends and cycles a very hard task.

${ }^{20}$ The fact that the expectation and variance of $q(t)-q(t-1)$ are both equal to $\lambda$ results from the distributional properties of a Poisson process. If the increment of the trend term was not constant, i.e. if e.g. $A$ was vintage dependent and stochastic, the expectation and variance would differ. This would be an interesting extension for future work and should help in empirical applications.
} 


\section{Volatility, welfare and taxation}

Given our measures of welfare and volatility derived in the last section, we can now ask how taxation affects these quantities.

\subsection{Volatility and taxation}

\subsubsection{The volatility channels}

Our central measure of volatility in (47) is affected through three channels: the speed of convergence $b_{1}$, the altitude of the slump $\hat{b}_{2}$ and the arrival rate $\lambda$. The interpretation of these parameters is based on (42) but other interpretations are possible. When we plot an arbitrary realization of our cyclical components in fig. 3, this becomes more transparent.

The range of our cyclical components is $] 0, b_{0} / b_{1}[$. The upper limit corresponds to the steady state $\hat{K}^{*}$ for the cyclical component of capital in fig. 1 . Hence, $b_{1}$ is at the same time a measure of the range of the cyclical component (cf. fig. 2, remembering that $b_{0}$ is only a scaling parameter) and thereby of its amplitude. The arrival rate $\lambda$ also measures the expected number of jumps or (the inverse of) the expected length of a cycle. The simple reason why volatility depends on taxation is therefore the same reason why the steady state capital stock (29) (i.e. the speed of convergence), the novelty of a new technology or the arrival rate depend on taxation.

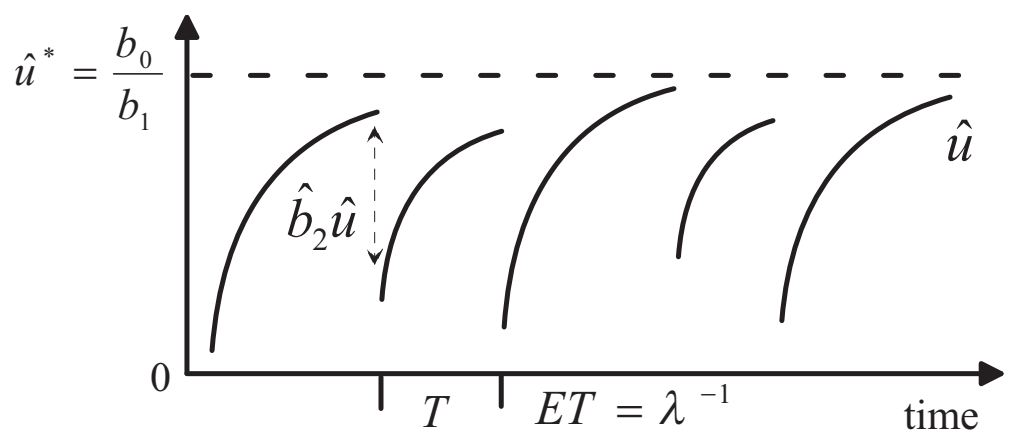

Figure 3: The cyclical components and their determinants $b_{1}, \hat{b}_{2}$ and $\lambda$

When we want to understand the effects of taxation, we can restrict attention to $b_{1}$ and $\lambda$ as $\hat{b}_{2}$ is independent of taxation. The independence of $\hat{b}_{2}$ (and of $b_{2}$ ) from taxes follows from their definitions in (34) and (41) and the fact that $\xi$ from (23), with $s$ from (16) and $\kappa_{0}$ from (6), is independent of tax rates. Economically, this independence of $\hat{b}_{2}$ follows from the fact that dividend payments $\kappa$ are not taxed and that economic depreciation $s$ does not imply tax-exemption as does physical depreciation $\delta$.

The tax effects on the arrival rate $\lambda$ are straightforward from looking at (22) and are summarized in table 1 . As the growth rate $g$ of expected utility has $\lambda$ as its only taxdependent determinant, it has the same qualitative properties and is also included in the table. The composite parameter $b_{1}$ in (28) depends on taxes both directly and indirectly through the arrival rate. When we insert (22) into (28), we obtain unambiguous results, 
except for $\tau_{I}$ (app. D.1.1).

\begin{tabular}{llllll}
\hline & $\tau_{L}=\tau_{K}{ }^{(*)}$ & $\tau_{C}$ & $\tau_{R}$ & $\tau_{I}$ & $\tau_{W}$ \\
\hline \hline$b_{1}$ & - & 0 & - & $+^{(1)}$ & + \\
$b_{2}, \hat{b}_{2}$ & 0 & 0 & 0 & 0 & 0 \\
$g, \lambda$ & 0 & 0 & - & + & 0 \\
\hline volatility & + & 0 & - & + & - \\
\hline welfare & - & - & \pm & \pm & - \\
\hline
\end{tabular}

$(*)$ only joint changes of $\tau_{L}$ and $\tau_{K}$ can be studied, see (24)

(1) for high $\tau_{I}$ or $\tau_{K}$ and low $\delta$

Table 1: Taxation effects on composite parameters, the arrival rate, volatility and welfare

\subsubsection{Comparative statics}

Let us now combine the effects of these three channels on volatility. As we have only two tax-dependent channels, $b_{1}$ and $\lambda$, taxation can affect volatility by either changing $\lambda$ or $b_{1}$ (without the $\lambda$ in $b_{1}$ ), or both. Clearly, when a tax has no effect on $b_{1}$ and $\lambda$, the $c v$ is not affected by this tax either. This is the case for taxation of consumption.

When taxing wealth, the arrival rate and the "slump parameter" $\hat{b}_{2}$ are not affected, while the (inverse) range parameter $b_{1}$ increases and, as a consequence, volatility goes down. Economically speaking, a tax on wealth decreases the households' return $r^{*}$ in (16) on savings and thereby implies a lower steady-state cyclical capital stock and utility level $\hat{u}$. Holding constant the length of a cycle but "squeezing" the cyclical components in fig. 3 , the relative dispersion must be lower.

An increase in the income tax on capital and labour reduces the range parameter $b_{1}$ but not the arrival rate $\lambda$. As a consequence, volatility unambiguously increases in this tax. How can this result be understood? The speed of convergence $b_{1}$ in (28) reduces for two reasons: (i) only net investment is taxed (as discussed before (15)), i.e. a higher tax on capital increases the positive effect of the refunding policy and reduces the impact of the depreciation rate $\delta$ as visible in (28). A lower (effective) depreciation rate increases incentives for capital accumulation and the steady-state capital stock increases. (ii) Due to our $\sigma=\alpha$ restriction, direct effects of joint changes in capital and labour taxation just cancel out and only this indirect refunding effect is left over. Clearly, this second effect would not survive for $\alpha \neq \sigma$ and $\tau_{K} \neq \tau_{L}$ and should potentially overcompensate the first effect. Hence, currently, the effect of income taxation is the opposite of wealth taxation but should go in similar directions for more general cases.

When analyzing R\&D and investment taxes $\tau_{R}$ and $\tau_{I}$, results are at first sight less clearcut as these taxes affect the arrival rate which affects the $c v$ directly positively and indirectly negatively through $\lambda$. Computing the derivatives, however, we get unambiguous results as presented in table 1 above (app. D.1.2). The analytics for $\tau_{R}$ say in words: a higher tax on research depresses the arrival rate. When the arrival rate falls, the ratio $b_{1} / \lambda$ increases and the $c v$ falls. Intuitively, a higher $\tau_{R}$ makes investment in research less profitable and the arrival rate $\lambda$ falls. Less frequent jumps in technology imply a lower volatility. A lower $\lambda$ also decreases $b_{1}$ which by fig. 3 implies a larger range $b_{0} / b_{1}$ and higher volatility. This is because $b_{1}$ represents physical depreciation but also consumption and expenditure for research. A lower $\lambda$ therefore implies ceteris paribus a lower $b_{1}$. This second indirect effect, however, is 
not large enough such that the direct volatility decreasing effect of higher taxes on research dominates.

Given the explanations for the previous finding, understanding the result for $\tau_{I}$ is also easy: a higher tax on investment increases the arrival rate which again has a direct and an indirect effect on volatility. The direct effect via the frequency of jumps overcompensates the indirect effect on the range and volatility increases. The additional effect of taxation on investment via the depreciation rate $\delta$ makes the range increasing effect of a higher $\lambda$ less strong such that the indirect effect is even weaker than under a change of $\tau_{R}$. Consequently, volatility falls more when $\tau_{I}$ increases as when $\tau_{R}$ falls.

If growth and volatility were exogenous, i.e. if there was an arrival rate given by $\lambda$ without any resources $R$ being required for R\&D, the model would from its basic structure resemble a simple RBC model. Any activity takes place under perfect competition and labour productivity improves by discrete amounts at random points in time. Volatility would still be affected by taxation as the arrival rate is only one out of three channels in our measure of volatility (47). ${ }^{21}$ As argued in the introduction, however, an endogenous arrival rate allows us to investigate whether taxes can explain a break in volatility without affecting the growth rate. As McConnell and Perez-Quiros (2000) argue, there was a break in volatility in the US in 1984 without a break in the trend of GDP. Hence, given our results in table 1, this model predicts falling income taxes $\tau_{L}=\tau_{K}$ and rising wealth taxes $\tau_{W}$ to reduce volatility without affecting trend growth.

\subsubsection{Quantitative importance}

This section takes a first look at the quantitative properties of our model and asks whether changes in tax rates can have effects that are "sufficiently large". Clearly, our analytically convinient approach of assuming the parameter restriction (24) imposes strong restrictions for calibration purposes. Calibration here is also more ambitous than in standard circumstances as we have additional statistical properties of observed economies which we want to match: Table 2 shows on the left-hand side that the average (expected) length of a cycle and growth rate $g$ and the tax elasticitiy of the growth rate enter as central predictions of the model. Reasonable values are obtained by choosing $A, D_{0}$ and the externality measure $\gamma$ (cf. app. D.1.3 for details) ${ }^{22}$. Initial tax rates and exogenous parameters were set at $\left(\tau_{I}, \tau_{R}, \tau_{C}, \tau_{F}, \tau_{W}\right)=(.15, .00, .15, .30, .01)$ and $\left(\alpha, \delta, \rho, \kappa_{0}\right)=\left(.5, .075, .03,10^{-12}\right)$, respectively. The exogenous parameter values for $\delta$ and $\rho$ are standard. The value for $\alpha$ depends on whether one perceives human capital to be captured by $K$ as well. We set it somewhat higher than the pure national account value of .3. Intuitively, the size of the new machine $\kappa$ is small relative to the capital stock in the economy as a whole. This explains the low value for $\kappa_{0}$.

\begin{tabular}{lll|lll} 
& \multicolumn{3}{c|}{ imposed } & \multicolumn{3}{|c}{ calibrated } \\
$E$ length of cycle & $E$ growth & tax elasticity of $\lambda$ & $A$ & $D_{0}$ & $\gamma$ \\
\hline \hline 5 years & $3 \%$ & 0.33 & 1.16 & $1.55 \times 10^{-10}$ & .75 \\
\hline
\end{tabular}

Table 2: A simple calibration

\footnotetext{
${ }^{21}$ The amount of volatility would therefore remain endogenous even in this exogenous shock economy. Volatility could, however, no longer be called "natural" as its source is exogenously imposed on the economy.

${ }^{22}$ Regression analyses show that the effect of taxation on growth is not without controversy: see e.g. Mendoza et. al. (1994) and Padovano and Galli (2001) for a survey.
} 


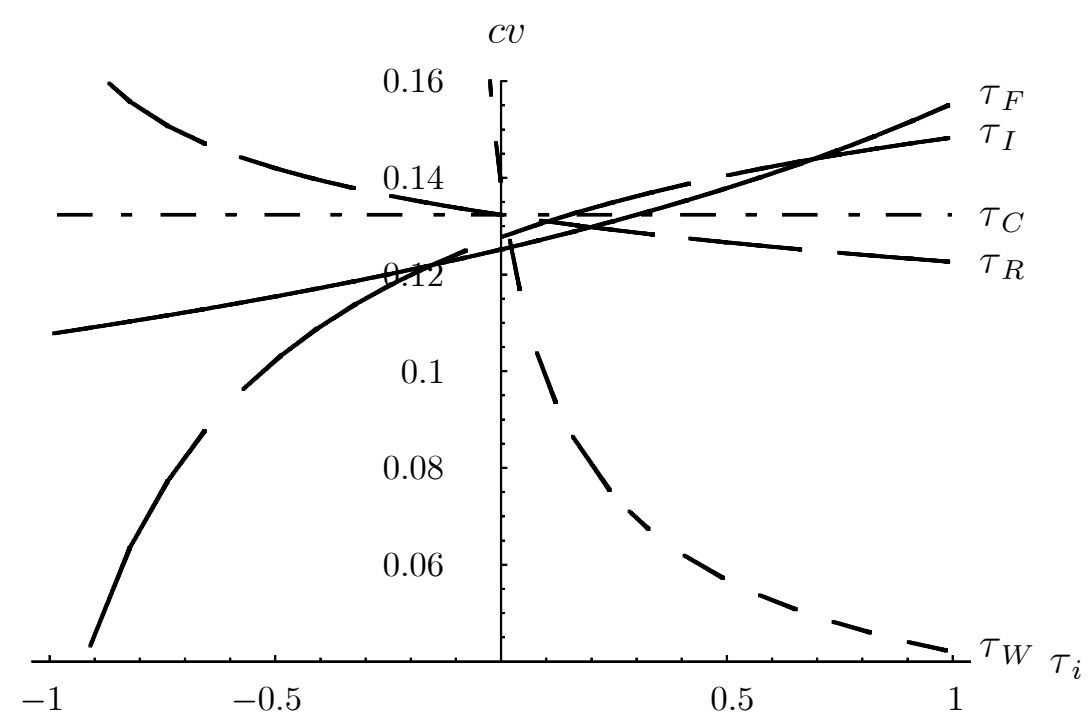

Figure 4: Quantitative dependence of the $c v$ on tax rates

Given these parameter values, fig. 4 shows the coefficient of variation as a function of tax rates. Taxes vary from -1 (a subsidy) to 1 . The coefficient of variation $(c v)$ of the baseline calibration is .13. The coefficient of variation for an HP-filtered cyclical component of real GDP for the U.S. economy decreased from about .4 in the 1955:2-1984:1 period to about .2 in 1984:2-2004:2. The decline in the variance of quarterly growth rates are of similar pattern (see e.g. McConnell and Perez-Quiros 2000). This implies that endogenous fluctuations of our model match roughly $33 \%$ to $65 \%$ of observed fluctuations (dividing .13 by .4 and .2 ). This is remarkable given the absence of exogenous sources of volatility or the $\sigma=\alpha$ restriction.

Some tax rates, i.e. the tax on research $\tau_{R}$ and the tax on wealth $\tau_{W}$ reduce the $c v$ of the baseline calibration potentially by $10 \%$ and $60 \%$, respectively. Other tax rates, i.e. the tax on investment $\tau_{I}$ and the factor income tax $\tau_{F}$ increase the $c v$ : a decrease of $\tau_{F}$ by 10 percentage points decreases the $c v$ roughly by $3 \%$. The break in volatility in the US could therefore be explained quantitatively only to some extent. It should be remembered, however, that tax effects enter only through the arrival rate $\lambda$ and the speed of convergence $b_{1}$. Effects of $\tau_{R}$ and $\tau_{I}$ on $\lambda$ are small by construction whereas effects on $b_{1}$ in (28) are - due to our explicit $\sigma=\alpha$ solution - only through $\tau_{W}$, the arrival rate $\lambda$, and the refunding effect, as direct effects of $\tau_{F}$ just cancel out. The consumption tax $\tau_{C}$ does not affect the $c v$ at all as the labourleisure choice is not modelled. We summarize our quantitative findings by stating that the level of tax rates does have an effect on volatility. A more elaborate calibration exercise (no parameter restriction, endogenous labour and some exogenous source of volatility) is needed, however, before the quantitative importance can be judged more convincingly.

\subsection{Volatility and welfare}

\subsubsection{The welfare channels and comparative statics}

When we look at our measure of welfare (39), it is affected by taxation through four quantities, average instantaneous utility $\mu$, current utility $u(c(t))$, and $g$ and $\beta$, the growth and convergence rate. These four quantities in turn depend on four channels, $b_{0}, b_{1}, \lambda$ and $\Psi$. We could now, following the approach from our measure of volatility, analyze the effects of taxation on these channels first and then combine the results and derive conclusions for 
welfare. As this does not yield additional insight, we directly link welfare to taxation by the following

Theorem 2 (Taxation and welfare) A tax reduces welfare (39) when the permanent component of welfare $\mu /(\rho-g)$ falls faster or increases less fast than the transition component $(\mu-u(t)) /(\rho-g+\beta)$. Computing the derivatives, we get

$$
\begin{aligned}
& \frac{\left(\frac{\partial b_{0}}{\partial \tau_{i}} \frac{1}{b_{0}}-\frac{\partial \beta}{\partial \tau_{i}} \frac{1}{\beta}\right)(\rho-g)+\frac{\partial \lambda}{\partial \tau_{i}}(\Theta-1)}{(\rho-g)^{2}} \\
& <\frac{\left(\frac{\partial b_{0}}{\partial \tau_{i}} \frac{1}{b_{0}}-\frac{\partial \beta}{\partial \tau_{i}} \frac{1}{\beta}-\frac{u(t)}{\mu} \frac{1-\sigma}{\Psi} \frac{\partial \Psi}{\partial \tau_{i}}\right)(\rho-g+\beta)-\left(\frac{\partial b_{1}}{\partial \tau_{i}}+\frac{\partial \lambda}{\partial \tau_{i}} b_{2}\right)\left(1-\frac{u(t)}{\mu}\right)}{(\rho-g+\beta)^{2}} .
\end{aligned}
$$

\section{Proof. app. D.2}

The left-hand side is the derivative of the permanent component of welfare, the righthand side is the derivative of the transition component (where both sides are divided by $\mu$ ). Both derivatives can be both negative or positive.

Going through these derivatives for individual taxes shows that (compare table 1 and app. D.2) taxes on factor income, consumption and wealth have unambiguous negative effects on welfare while taxes on investment and R\&D can increase welfare. Taxes $\tau_{F}, \tau_{C}$ and $\tau_{W}$ decrease welfare as resources are taken away from households and $G$ has in the model no productivity- or utility-enhancing effect. The potentially welfare increasing effect of $\tau_{I}$ and $\tau_{R}$ can best be understood when looking at the first order condition for investment in research: in our decentralized setup, the first order condition $\left(1+\tau_{R}\right) V_{a}(a(t), q)$ $=\lambda V_{\tilde{a}}(\tilde{a}, q+1) \frac{\left(1+\tau_{I}\right) \kappa}{R}$ from (A.17) shows that individuals invest in R\&D because of dividend payments $\kappa^{*}$, their increased wealth $\tilde{a}$ and the better technology $q+1$. Optimal investment in a planner economy, where the planner maximizes the Bellman equation (A.15) with respect to $R$ rather than $i$ and where $\Sigma a(t)$ stands for wealth in the economy as a whole, would satisfy $V_{\Sigma a}(\Sigma a(t), q)=\frac{\partial \lambda}{\partial R}[V(\Sigma \tilde{a}, q+1)-V(\Sigma a, q)]$. Incentives to do research therefore results from $\partial \lambda / \partial R$, the effect of more resources on the probability $\lambda$ to find a new technology, and the difference in well-being between a situation with more wealth and a better technology, $V(\Sigma \tilde{a}, q+1)$, and today, $V(\Sigma a, q)$. While there are certainly various opposing effects, externalities are strongest for this trade-off between capital accumulation and R\&D. It is therefore not surprising, that taxes $\tau_{I}$ and $\tau_{R}$ which are directly affecting this first order condition are best suited to potentially internalize externalities.

As the first order conditions for consumption is identical for the planner and the representative household, there are no externalities or imperfections present in the model apart from those visible in the difference between the first order conditions for R\&D. Put differently, if the arrival rate equalled $\lambda$ exogenously without any resources $R$ being allocated to R\&D, the decentralized economy would be efficient. This RBC-type version of our model would then predict that fluctuations allow for an optimal adjustment by individuals to exogenous disturbances. If one believes, however, that the process of finding and developing new technologies implies certain externalities (and that new technologies at least partially induce fluctuations), factor allocations in an economy "growing through cycles", to use Matsuyama's (1999) words, are inefficient. 


\subsubsection{The tax-link between volatility and welfare}

Given the inefficiency of fluctuations, should taxes be used to stabilize the economy? In the literature, more volatility is usually associated with lower welfare: In perfect-market models (Lucas, 1987, 2003 or, more recently, Epaulard and Pommeret, 2003 and Barlevy, 2004), exogenous volatility implies fluctuations of consumption and the curvature of the utility function implies lower welfare than in an economy without fluctuations but identical average growth. Gali et al. (2003) focus on inefficiencies and argue - due to the inefficiency of the steady state and the larger welfare losses in recessions than welfare gains in booms - that fluctuations on average cause welfare losses.

This is not necessarily the case when fluctuations are endogenous: While the curvature of the utility function à la Lucas and the asymmetry as in Gali (and others) is welfare-reducing in our setup as well, volatility is only the result of the more fundamental factor allocation in an economy. Asking whether volatility is welfare reducing and by how much is therefore meaningful only if one believes that the sources of fluctuations are exogenous to an economy (which, in the real world, they are - to a certain extent). The welfare effects of endogenous fluctuations, however, can only be understood when understanding the welfare properties of the underlying factor allocation that causes these fluctuations. When this is done, it becomes clear that more or less fluctuations can be associated (and are not causal as in the exogenous fluctuation case) with higher or lower welfare. Tax policy should therefore not be used in all cases to stabilize the economy.

This association between welfare and volatility, illustrated for taxes with unambiguous welfare effects, is depicted in the following figure.

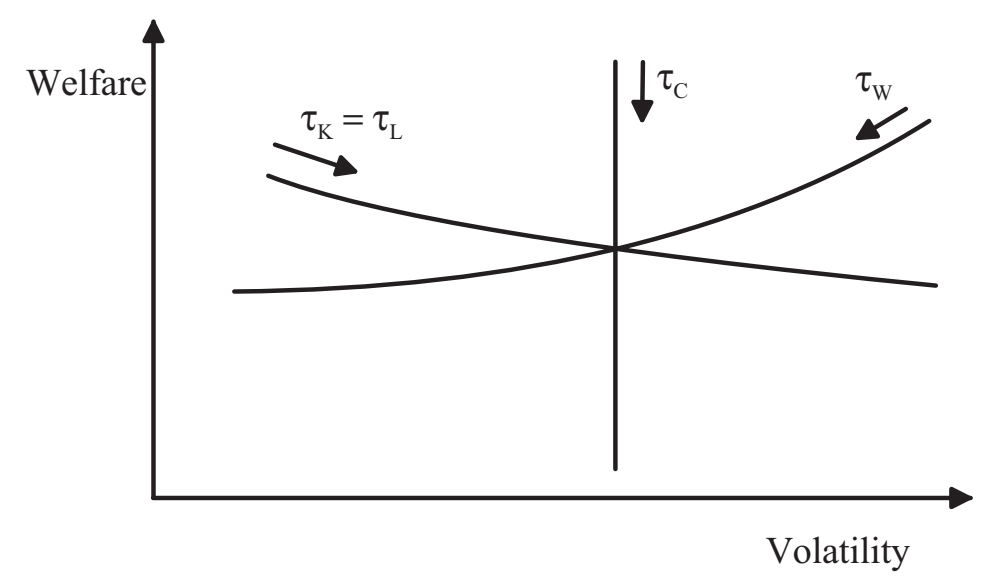

Figure 5: Welfare, volatility and taxation - anything goes

Arrows indicate in which direction to move on the line when the tax is increased. Fig. 5 shows that there is no association between volatility and welfare in general. It all depends on the source of the change in volatility. While certain taxes increase volatility and reduce welfare $\left(\tau_{F}\right)$, others reduce volatility but still decrease welfare $\left(\tau_{W}\right)$. Lowering the tax on wealth increases welfare as fewer resources are taken away from the economy as argued above. At the same time, volatility increases as the steady state capital stock (29) increases. Hence, despite the curvature of the utility function and the asymmetric effect of volatility on efficiency, more volatility implies higher welfare. 


\section{Conclusion}

Growth rates above and below long-run trends are a common feature of all real-world economies. The present paper used a model that perceives endogenous fluctuations as a natural phenomenon of all endogenously growing economies by stipulating that new technologies increase labour productivity in a discrete way. Agents in this setup are not solely responding to shocks but rather are the source of shocks, i.e. jumps in technologies, due to their financing of innovation and growth. This framework was used to analyze the effects of taxation on volatility and the associated welfare effects. Due to a sharp decrease of volatility in the US and an almost simultaneous strong tax reform, taxation was expected to potentially explain part of the 'big moderation' starting in 1983.

We used the coefficient of variation of the cyclical component of a typical time series as our measure of volatility. It was shown that this measure is most tractable from a theoretical perspective and that three economically meaningful channels affect this measure: potential range of cyclical components, slumps and frequency of new technologies. Taxes affect these channels in various ways which allows, inter alia, to understand a change in volatility without requiring a simultaneous change in the growth rate of the economy.

Welfare effects associated with changes in volatility can be manifold. In a special case of our model where the source of long-run growth and short-run fluctuations is exogenous, factor allocation is efficient and volatility does not signal the need for stabilization. With endogenous growth and fluctuations, however, inefficiencies enter the economy and fluctuations hint at the possibility of welfare-increasing policy measures, even though all production and $R \& D$ activities were modelled to take place under perfect competition.

Stabilization is not necessarily welfare increasing, however: Lower volatility can imply higher or lower welfare, depending on whether the tax change reducing volatility implies higher or lower welfare. Analyzing the link between volatility and welfare should therefore not be restricted to the usual mono-causal link from an exogenous source of volatility and an endogenous welfare reaction but expanded to exogenous change in fiscal policy (or other exogenous changes in the economic environment) and how natural volatility and welfare react to this.

An important extension of the present analysis (and other papers in the literature on endogenous fluctuations and growth) would combine endogenous and exogenous sources of fluctuations. It appears reasonable to start an analysis of fluctuations of any real word economy by allowing for both endogenous jumps of and exogenous shocks to the technology as well as nominal sources of fluctuations. Labour market participation decisions and unemployment should also be included in future work. The implications of our analysis for the growth and volatility debate could also be worked out more precisely. With endogenous volatility, taxes (or other policy parameters) affect both long-run growth and volatility. As in our welfare argument, the causal link from volatility on growth becomes a correlation. The implied endogeneity of volatility in regression analyses could be tested.

\section{Appendix}

This appendix contains derivations that are interesting from a theoretical perspective beyond this specific paper. Section 7.1 derives the evolution of expected instantaneous utility. It uses methods that were developed in the applied mathematical literature, e.g. Garcia and Griego (1994). These methods are potentially useful also in other areas where Poisson processes are 
used (e.g. all search and matching models in monetary or labour economics). Section 7.2 computes an explicit expression for the variance of the growth rate. Again, various methods are borrowed from Garcia and Griego (1994). Finally, section 7.3 computes the moments of our basic random variable. This forms the basis for our measure of volatility. Interestingly, we obtain a generalized $\beta$-distribution from this analysis.

Further derivations are included in the Referees' appendix which is available upon request.

\subsection{Evolution of expected instantaneous utility}

This section computes the expected value of instantaneous utility, conditional on the current state in $t$, given by $q(t)$ and $K(t)$. The results provide information about expected growth but are especially needed for computing the value function.

\subsubsection{A lemma for $E\left(c^{k N_{\tau}}\right)$}

We first compute some simple expectations that are used later.

Lemma 3 Assume that we are int and form expectations about future arrivals of the Poisson process. The expected value of $c^{k q(\tau)}$, conditional on $t$ where $q(t)$ is known, is

$$
E_{t}\left(c^{k q(\tau)}\right)=c^{k q(t)} e^{\left(c^{k}-1\right) \lambda(\tau-t)}, \quad \tau>t, \quad c, k=\text { const } .
$$

Note that for integer $k$, these are the raw moments of $c^{q(\tau)}$.

Proof. We can trivially rewrite $c^{k q(\tau)}=c^{k q(t)} c^{k[q(\tau)-q(t)]}$. At time $t$, we know the realization of $q(t)$ and therefore $E_{t} c^{k q(\tau)}=c^{k q(t)} E_{t} c^{k[q(\tau)-q(t)]}$. Computing this expectation requires the probability that a Poisson process jumps $n$ times between $t$ and $\tau$. Formally,

$$
\begin{aligned}
E_{t} c^{k[q(\tau)-q(t)]} & =\sum_{n=0}^{\infty} c^{k n} \frac{e^{-\lambda(\tau-t)}(\lambda(\tau-t))^{n}}{n !}=\sum_{n=0}^{\infty} \frac{e^{-\lambda(\tau-t)}\left(c^{k} \lambda(\tau-t)\right)^{n}}{n !} \\
& =e^{\left(c^{k}-1\right) \lambda(\tau-t)} \sum_{n=0}^{\infty} \frac{e^{-\lambda(\tau-t)-\left(c^{k}-1\right) \lambda(\tau-t)}\left(c^{k} \lambda(\tau-t)\right)^{n}}{n !} \\
& =e^{\left(c^{k}-1\right) \lambda(\tau-t)} \sum_{n=0}^{\infty} \frac{e^{-c^{k} \lambda(\tau-t)}\left(c^{k} \lambda(\tau-t)\right)^{n}}{n !}=e^{\left(c^{k}-1\right) \lambda(\tau-t)}
\end{aligned}
$$

where $\frac{e^{-\lambda \tau}(\lambda \tau)^{n}}{n !}$ is the probability of $q(\tau)=n$ and $\sum_{n=0}^{\infty} \frac{e^{-c^{k} \lambda(\tau-t)}\left(c^{k} \lambda(\tau-t)\right)^{n}}{n !}=1$ denotes the summation of the probability function over the whole support of the Poisson distribution which was used in the last step.

Lemma 4 Assume that we are in $t$ and form expectations about future arrivals of the Poisson process. Then the number of expected arrivals in the time interval $[\tau, s]$ equals the number of expected arrivals in an unknown time interval of the length $\tau-s$ and therefore

$$
E_{t}\left(c^{k[q(\tau)-q(s)]}\right)=E\left(c^{k[q(\tau)-q(s)]}\right)=e^{\left(c^{k}-1\right) \lambda(\tau-s)}, \quad \tau>s>t, \quad c, k=\text { const } .
$$

Proof. This proof is in appendix C.1.1, it simply applies lemma 3. 


\subsubsection{Expected instantaneous utility}

We will use in what follows the martingale property of various expressions. These expressions are identical to or special cases of $\int_{t}^{\tau} f(q(s), s) d q(s)-\lambda \int_{t}^{\tau} f(q(s), s) d s$, of which Garcia and Griego (1994, theorem 5.3) have shown that it is a martingale indeed, i.e.

$$
E_{t}\left[\int_{t}^{\tau} f(q(s), s) d q(s)-\lambda \int_{t}^{\tau} f(q(s), s) d s\right]=0,
$$

where $\lambda$ is the (constant) arrival rate of $q(s)$.

The integral version of (33) for $\tau>t$ is $u(\tau)=u(t)+\int_{t}^{\tau} b_{0} \Theta^{q(s)}-b_{1} u(s) d s-\int_{t}^{\tau} b_{2} u(s) d q(s)$. Applying (conditional) expectation operators gives $E_{t} u(\tau)=u(t)+E_{t} \int_{t}^{\tau} b_{0} \Theta^{q(s)} d s-E_{t} \int_{t}^{\tau} b_{1} u(s) d s$ $-E_{t} \int_{t}^{\tau} b_{2} u(s) d q(s)$. When we pull expectations into the integral (as in equation (30)), use lemma 3 and the martingale result (48), we get $E_{t} u(\tau)=u(t)+\Theta^{q(t)} \int_{t}^{\tau} b_{0} e^{(\Theta-1) \lambda[s-t]} d s$ $-\int_{t}^{\tau} b_{1} E_{t} u(s) d s-\lambda \int_{t}^{\tau} b_{2} E_{t} u(s) d s$. With $m_{1}(\tau) \equiv E_{t} u(\tau)$ from $(31)$, we get $m_{1}(\tau)=u(t)$ $+\int_{t}^{\tau} \Theta^{q(t)} b_{0} e^{(\Theta-1) \lambda[s-t]} d s-\int_{t}^{\tau} b_{1} m_{1}(s) d s-\int_{t}^{\tau} b_{2} \lambda m_{1}(s) d s$ and differentiating with respect to time $\tau$ gives

$$
\dot{m}_{1}(\tau)=\Theta^{q(t)} b_{0} e^{(\Theta-1) \lambda[\tau-t]}-\left(b_{1}+\lambda b_{2}\right) m_{1}(\tau) .
$$

The solution of this deterministic linear differential equation is

$$
\begin{aligned}
m_{1}(\tau) & =m_{1}(t) e^{-\left(b_{1}+\lambda b_{2}\right)(\tau-t)}+\int_{t}^{\tau} \Theta^{q(t)} b_{0} e^{(\Theta-1) \lambda[s-t]} e^{-\left(b_{1}+\lambda b_{2}\right)(\tau-s-\tau+t)} e^{-\left(b_{1}+\lambda b_{2}\right)(\tau-t)} d s \\
& =e^{-\left(b_{1}+\lambda b_{2}\right)(\tau-t)}\left(m_{1}(t)+\Theta^{q(t)} b_{0} \int_{t}^{\tau} e^{\left(b_{1}+\lambda b_{2}+(\Theta-1) \lambda\right)(s-t)} d s\right) \\
& =e^{-(\beta-g)(\tau-t)}\left(u(t)+\Theta^{q(t)} b_{0} \frac{e^{\beta[\tau-t]}-1}{\beta}\right),
\end{aligned}
$$

where the last line used $m_{1}(t)=E_{t} u(t)=u(t)$ and (36) for $\beta$. Rearranging gives (37) in the text.

\subsection{The variance of the growth rate}

This section derives an alternative expression for volatility, the variance of the growth rate. This measure is more common in empirical work (e.g. Ramey and Ramey, 1995 or McConnell and Perez-Quiros, 2000) than the variance of cyclical components, which in turn is used more intensively in the RBC literature.

It is not immediately clear, however, how this variance should be computed. Is it the variance of some long-run stationary distribution, $\lim _{\tau \rightarrow \infty} \operatorname{var}_{t}\left[g_{\tau, t}\right]$, is it the variance of some "annual" growth rate of some long-run distribution, $\lim _{\tau \rightarrow \infty} \operatorname{var}_{t}\left[g_{\tau+1, \tau}\right]$, or is it the variance of the next "period" in this model, $\operatorname{var}_{t}\left[g_{t+1, t}\right]$ ? In a way, the choice of measure of variance is arbitrary. We therefore choose the one that comes closest to the estimation of the variance of observed growth rates. The counterpart to an observed annual growth rate for a "year" $t$ in our model is $g_{t+1, t}$. Taking many drawings, there is a set of annual growth rates $\left\{g_{t+1, t}\right\}$ for which the variance can be estimated. Noting that annual growth rates are computed given the knowledge on $t$, the analytical expression corresponding to this is the $t$-contingent variance of $g_{t+1, t}$, i.e. $\operatorname{var}_{t}\left[g_{t+1, t}\right]$.

Now, we can take advantage of the following straightforward relationship: The $t$-contingent variance of the growth rate of some random variable is the same as the $t$-contingent variance 
of the random variable divided by some constant. In our case,

$$
\operatorname{var}_{t}\left[\frac{u(\tau)-u(t)}{u(t)}\right]=\frac{\operatorname{var}_{t} u(\tau)}{u(t)^{2}} .
$$

While this is trivial in a sense, it has the huge advantage that we can just compute the second moment of $u(\tau)$ and thereby obtain the theoretical counterpart of the variance of observed growth rates.

The variance of $u(\tau)$ is computed by first computing its second moment. To this end, the evolution of squared utility needs to be understood. It follows (app. C.2.2)

$$
d u(t)^{2}=2\left(b_{0} \Theta^{q(t)} u(t)-b_{1} u(t)^{2}\right) d t-\left(1-\left(1-b_{2}\right)^{2}\right) u(t)^{2} d q .
$$

Comparing it to (33) shows that the main difference, apart from the square term $u^{2}$ instead of $u$, is the interaction $\Theta^{q} u$ between $\Theta^{q}$ and $u$. When forming expectations, we therefore have to compute the expected interaction term, i.e. look at $\psi(s) \equiv E_{t} \Theta^{q(s)} u(s)$. After "some steps" (filling 6 pages in app. C.2), denoting

$$
\begin{gathered}
g_{\psi} \equiv\left(\Theta^{2}-1\right) \lambda>0 \\
\beta_{\psi} \equiv g_{\psi}+b_{1}+\left(1-\Theta\left[1-b_{2}\right]\right) \lambda=b_{1}+\left(\Theta^{2}-\Theta \Xi\right) \lambda>0 \\
\beta_{2} \equiv g_{\psi}+2 b_{1}+\left(1-\left(1-b_{2}\right)^{2}\right) \lambda
\end{gathered}
$$

the variance from (A.49) is

$$
\begin{aligned}
\operatorname{var}_{t}(u(\tau))= & \mu^{2}\left[e^{-\left(\beta_{2}-g_{\psi}\right)(\tau-t)}\left(\frac{u(t)^{2}}{\mu^{2}}-\frac{2 \beta^{2}}{\beta_{2} \beta_{\psi}}\right)+\frac{2 \beta^{2}}{\beta_{2} \beta_{\psi}} e^{g_{\psi}[\tau-t]}\right. \\
& \left(e^{-\left(\beta_{\psi}-g_{\psi}\right)(\tau-t)}-e^{-\left(\beta_{2}-g_{\psi}\right)(\tau-t)}\right) \frac{2 \beta}{\beta_{2}-\beta_{\psi}}\left(\frac{u(t)}{\mu}-\frac{\beta}{\beta_{\psi}}\right) \\
& \left.-e^{2 g[\tau-t]}\left[e^{-\beta[\tau-t]}\left(\frac{u(t)}{\mu}-1\right)+1\right]^{2}\right]
\end{aligned}
$$

The structure of the variance is similar to previous structures in e.g. (37) for expected utility. There are growth and convergence rates (51) and there are expected long-run quantities. As a measure of volatility, however, the variance of the growth rate is less suitable for a variety of reasons: First, when we let $\tau$ become very large, i.e. when we look at the "long run" $T \gg t$, we do get a simpler expression as all convergence terms disappear (appendix C.2.3),

$$
\frac{\operatorname{var}_{t}(u(T))}{u(t)^{2}}=\frac{\mu^{2}}{u(t)^{2}}\left(\frac{2 \beta^{2}}{\beta_{2} \beta_{\psi}} e^{g_{\psi}[T-t]}-e^{2 g[T-t]}\right) .
$$

This expression, however, represents the variance of the growth rate between $t$ and $T$, i.e. we would not compute the variance of annual growth rates but of $T-t$-year growth rates. Clearly, such a variance can never be estimated in reality. Second, the expression for the variance for annual growth rates, i.e. growth rates from $t$ to $t+1$, is the complete expression in (A.50) for $\tau=t+1$. Understanding properties of this expression, like derivatives with respect to certain tax rates appears analytically hopeless. Third, as a potential theoretical way out, one could try and deterministically detrend $u(\tau)$ as discussed on page 14. Computing the variance of the growth rate of deterministically detrended $u(\tau)$ (and not of $u(\tau)$ as done here), however, does not yield a finite expression either as the variance grows at $g_{\psi}$ while inserting $e^{-g[\tau-t]}$ in front of $u(\tau)$ in (50) would not compensate for $g_{\psi}$. 


\subsection{The cyclical component}

\subsubsection{The basic differential equation (42)}

As $\hat{u}=(\hat{C} / L)^{1-\sigma} /(1-\sigma)$ from $(40)$, we have $d \hat{u}=\frac{(1 / L)^{1-\sigma}}{1-\sigma} d \hat{C}^{1-\sigma}$. With $\hat{C}=\Psi \hat{K}$ from (19), (26) and the change of variable formula (CVF), we obtain

$$
\begin{gathered}
d \hat{C}^{1-\sigma}=\Psi^{1-\sigma} d \hat{K}^{1-\sigma} \\
=\left(\frac{b_{0}}{\Psi^{1-\sigma}} \hat{K}^{\alpha} L^{1-\alpha}-\frac{b_{1}}{1-\sigma} \hat{K}\right)(1-\sigma) \Psi^{1-\sigma} \hat{K}^{-\sigma} d t+\left(\left(1-\left(1-A^{-1} \xi\right)\right)^{1-\sigma}-1\right) \Psi^{1-\sigma} \hat{K}^{1-\sigma} d q \\
=\left(b_{0} \hat{K}^{\alpha-\sigma} L^{1-\alpha}(1-\sigma)-b_{1} \hat{C}^{1-\sigma}\right) d t+\left(\left(A^{-1} \xi\right)^{1-\sigma}-1\right) \hat{C}^{1-\sigma} d q \\
=\left(b_{0} \hat{K}^{\alpha-\sigma} L^{1-\alpha}(1-\sigma)-b_{1} \hat{C}^{1-\sigma}\right) d t-(1-\Xi / \Theta) \hat{C}^{1-\sigma} d q .
\end{gathered}
$$

Using $\sigma=\alpha$ from (24), inserting and simplifying yields

$$
\begin{aligned}
d \hat{u} & =\frac{(1 / L)^{1-\sigma}}{1-\sigma}\left[\left(b_{0} \hat{K}^{\alpha-\sigma} L^{1-\alpha}(1-\sigma)-b_{1} \hat{C}^{1-\sigma}\right) d t-(1-\Xi / \Theta) \hat{C}^{1-\sigma} d q\right] \\
& =\left(b_{0}-b_{1} \hat{u}\right) d t-(1-\Xi / \Theta) \hat{u} d q .
\end{aligned}
$$

\subsubsection{Computing moments}

The integral version of (42) for $\tau>t$ is $\hat{u}(\tau)=\hat{u}(t)+\int_{t}^{\tau}\left(b_{0}-b_{1} \hat{u}(s)\right) d s-\int_{t}^{\tau} \hat{b}_{2} \hat{u}(s) d q(s)$.

Using the martingale result (48), the expected value of $\hat{u}(\tau)$ is $E_{t} \hat{u}(\tau)=\hat{u}(t)+\int_{t}^{\tau}\left(b_{0}-b_{1} E_{t} \hat{u}(s)\right) d s-$ $\lambda \int_{t}^{\tau} \hat{b}_{2} E_{t} \hat{u}(s) d s$. This describes the evolution of the first moment of $\hat{u}$. Expressed as a differential equation and using the definition in (43), we obtain $\dot{\hat{m}}_{1}(\tau)=b_{0}-\left(b_{1}+\lambda \hat{b}_{2}\right) \hat{m}_{1}(\tau)$. The solution of this deterministic linear differential equation is $\hat{m}_{1}(\tau)=$ $e^{-\left(b_{1}+\lambda \hat{b}_{2}\right)(\tau-t)}\left(\hat{m}_{1}(t)+\int_{t}^{\tau} e^{\left(b_{1}+\lambda \hat{b}_{2}\right)(s-t)} b_{0} d s\right)=e^{-\left(b_{1}+\lambda \hat{b}_{2}\right)(\tau-t)}\left(\hat{m}_{1}(t)+b_{0} \frac{e^{\left(b_{1}+\lambda \hat{b}_{2}\right)(\tau-t)}-1}{b_{1}+\lambda \hat{b}_{2}}\right)$, which can be simplified to

$$
\hat{m}_{1}(\tau)=e^{-\left(b_{1}+\lambda \hat{b}_{2}\right)(\tau-t)}\left(\hat{m}_{1}(t)-\frac{b_{0}}{b_{1}+\lambda \hat{b}_{2}}\right)+\frac{b_{0}}{b_{1}+\lambda \hat{b}_{2}} .
$$

As $b_{1}+\lambda \hat{b}_{2}>0$, the first moment of $\hat{u}$ is in the long run given by $\hat{m}_{1}(\infty) \equiv \lim _{\tau \rightarrow \infty} \hat{m}_{1}(\tau)=$ $\frac{b_{0}}{b_{1}+\lambda \hat{b}_{2}}$, as presented in (44).

For higher moments, the basic differential equation determining the evolution of $\hat{u}^{n}$ is from $(42)$

$$
\begin{aligned}
d \hat{u}^{n} & =n \hat{u}^{n-1}\left[b_{0}-b_{1} \hat{u}\right] d \tau-\left(1-\left(1-\hat{b}_{2}\right)^{n}\right) \hat{u}^{n} d q \\
& =n\left[b_{0} \hat{u}^{n-1}-b_{1} \hat{u}^{n}\right] d \tau-\left(1-\left(1-\hat{b}_{2}\right)^{n}\right) \hat{u}^{n} d q .
\end{aligned}
$$

Using the integral version, applying expectations and the martingale result (48), we obtain $d E_{t} \hat{u}^{n}=\left(n b_{0} E_{t} \hat{u}^{n-1}-\left(n b_{1}+\lambda\left[1-\left(1-\hat{b}_{2}\right)^{n}\right]\right) E_{t} \hat{u}^{n}\right) d t$. Using again (43),

$$
\dot{\hat{m}}_{n}=n b_{0} \hat{m}_{n-1}-\left(n b_{1}+\lambda\left[1-\left(1-\hat{b}_{2}\right)^{n}\right]\right) \hat{m}_{n} .
$$


It can now be shown that all moments are constant for $\tau \rightarrow \infty$. This follows from (54) for the first moment and from appendix C.3.1 for the 2nd moment. This proof simply inserts (54) into (55) and solves the differential equation. Proofs for higher moments would follow an identical approach. Hence, for the long run where $\dot{\hat{m}}_{n}=0$, we have from (56)

$$
\hat{m}_{n}(\infty)=\frac{n b_{0}}{n b_{1}+\lambda\left[1-\left(1-\hat{b}_{2}\right)^{n}\right]} \hat{m}_{n-1}(\infty) .
$$

By inserting $n=2$, this directly implies (45), with $n=1$, it becomes (44), remembering that $\hat{m}_{0}=1$ by definition.

A well-known theorem states that a distribution with limited range is completely characterized by its integer moments (e.g. Casella and Berger, 1990, th. 2.3.3.). As our long-run moments are constant and the range of $\hat{u}$ is finite, the distribution of $\hat{u}$ exists, is unique and stationery. Looking at the structure of moments in (57) further shows that the distribution of $\hat{u}$ is some generalized $\beta$-distribution: If $\hat{b}_{2}=1,(57)$ can be written as $m_{n}^{c}(\infty)=\frac{n b_{0}}{n b_{1}+\lambda} m_{n-1}^{c}(\infty)$. Starting from $\hat{m}_{0}=1$, repeated inserting yields

$$
m_{n}^{c}(\infty)=\frac{b_{0}^{n} n !}{\prod_{i=1}^{n}\left(i b_{1}+\lambda\right)}=\left(\frac{b_{0}}{b_{1}}\right)^{n} \frac{\Gamma(n+1)}{\prod_{i=1}^{n}\left(i+\lambda / b_{1}\right)}=\left(\frac{b_{0}}{b_{1}}\right)^{n} \frac{\Gamma(n+1) \Gamma\left(1+\lambda / b_{1}\right)}{\Gamma\left(n+1+\lambda / b_{1}\right)},
$$

where $\Gamma(\cdot)$ is the gamma-function. The last expression represents, apart from the scaling factor $\left(b_{0} / b_{1}\right)^{n}$, the $n$th moment of a $\beta$-distribution with parameters 1 and $\lambda / b_{1}$. (On the $\beta$-distribution, see e.g. Johnson, Kotz and Balakrishnan (1995, ch. 25).) Since the $\beta$ distribution is determined by its moments, we conclude that, for $\hat{b}_{2}=1, \hat{u}$ has the asymptotic representation $\hat{u}=\left(\frac{b_{0}}{b_{1}}\right)^{n} X$, where $X \sim \operatorname{Beta}\left(1, \lambda / b_{1}\right)$. When $\hat{b}_{2} \neq 1$, we therefore obtain a generalized $\beta$-distribution which, to the best of our knowledge, has not been encountered before. Analyzing its properties in detail will have to be done in future research. We are indebted to Christian Kleiber for pointing this out to us. For related aspects, see Kleiber and Kotz (2003).

\section{References}

Aghion, P. (2002): "Schumpeterian Growth Theory and the Dynamics of Income Inequality," Econometrica, 70(3), 855-882.

Aghion, P., A. Banerjee, and T. Piketty (1999): "Dualism and macroeconomic volatility," Quarterly Journal of Economics, 114(4), 1359-1397.

Aghion, P., and P. Howitt (1992): "A Model of Growth Through Creative Destruction," Econometrica, 60(2), 323-351.

Auerbach, A. J., and J. Slemrod (1997): "The Economic Effects of the Tax Reform Act of 1986," Journal of Economic Literature, 35, 589-632.

Bai, J., and S. Ng (2004): "A PANIC Attack on Unit Roots and Cointegration," Econometrica, $72,1127-1177$.

Barlevy, G. (2004): "The Cost of Business Cycles Under Endogenous Growth," American Economic Review, 94, 964 - 990. 
Barro, R. J., and X. Sala-i-Martín (1995): Economic Growth. McGraw-Hill, New York.

Benhabib, J., and A. Rustichini (1994): "A note on a new class of solutions to dynamic programming problems arising in economic growth," Journal of Economic Dynamics and Control, 18, 807-813.

Bental, B., and D. Peled (1996): "The Accumulation of Wealth and the Cyclical Generation of New Technologies: A Search Theoretic Approach," International Economic Review, $37(3), 687-718$.

Beveridge, S., and C. R. Nelson (1981): "A New Approach to Decomposition of Economic Time Series into Permanent and Transitory Components with Particular Attention to Measurement of the 'Business Cycle'," Journal of Monetary Economics, 7, 151-174.

Boldrin, M., and D. Levine (2004): "IER Lawrence Klein lecture: The case against intellectual monopoly," International Economic Review, 45, 327-350.

Burnside, C., M. Eichenbaum, and J. D. Fisher (2004): "Fiscal Shocks and their consequences," Journal of Economic Theory, 115, 89-117.

Casella, G., and R. L. Berger (1990): Statistical inference. Duxbury, Pacific Grove, CA.

Chari, V., P. J. Kehoe, and E. R. McGrattan (2000): "Sticky Price Models of the Business Cycle: Can the Contract Multiplier Solve the Persistence Problem?," Econometrica, 68, $1151-1179$.

de Hek, P. (1999): "On Endogenous Growth Under Uncertainty," International Economic Review, 40, 727-744.

Epaulard, A., and A. Pommeret (2003): "Recursive Utility, Endogenous Growth, and the Welfare Cost of Volatility," Review of Economic Dynamics, 6(2), 672-684.

Fatás, A. (2000): "Endogenous Growth and Stochastic Trends," Journal of Monetary Economics, 45, 107-128.

Fatás, A., and I. Mihov (2003): "The Case For Restricting Fiscal Policy Discretion," Quarterly Journal of Economics, November, 1419-1447.

Francois, P., and H. Lloyd-Ellis (2003): "Animal Spirits Trough Creative Destruction," American Economic Review, 93(3), 530-550.

Funk, P. (1996): "Endogenous Growth, Temporary Equilibrium, and the Direction of Change," Discussion Paper No A-506, University of Bonn.

Galí, J., M. Gertler, and J. D. Lopez-Salido (2003): "Markups, Gaps, and the Welfare Costs of Business Fluctuations," Rev. Version of NBER Working Paper, 8850.

García, M. A., and R. J. Griego (1994): "An Elementary Theory of Stochastic Differential Equations Driven by A Poisson Process," Commun. Statist. - Stochastic Models, 10(2), $335-363$.

Greenwood, J., and G. W. Huffman (1991): "Tax Analysis in a Real-Business-Cycle Model," Journal of Monetary Economics, 27, 167-190. 
Hellwig, M., and A. Irmen (2001): "Endogenous Technical Change in a Competitive Economy," Journal of Economic Theory, 101, 1 - 39.

Johnson, N. L., S. Kotz, and N. Balakrishnan (1995): Continuous Univariate Distributions, Vol. 2, 2nd edition. Wiley.

Jones, J. B. (2002): "Has Fiscal Policy Helped Stabilize the U.S. Economy?," Journal of Monetary Economics, 49, 709-746.

Kehoe, P. J., and F. Perri (2002): "International Business Cycles with Endogenous Incomplete Markets," Econometrica, 70, 907-928.

Kim, C.-J., and C. R. Nelson (1999): "Has the U.S. Economy Become More Stable? A Bayesian Approach Based on a Markov-Switching Model of the Business Cycle," The Review of Economics and Statistics, 81, 608-616.

King, R. G., C. I. Plosser, and S. T. Rebelo (1988): "Production, Growth and Business Cycles II. New Directions," Journal of Monetary Economics, 21, 309-341.

King, R. G., C. I. Plosser, J. H. Stock, and M. W. Watson (1991): "Stochastic Trends and Economic Fluctuations," American Economic Review, 81(4), 819-840.

King, R. G., and S. T. Rebelo (1999): Resuscitating Real Business Cycles. in J.B. Taylor and M. Woodford, Eds., Handbook of Macroeconomics, Volume 1, 9271007.

Kleiber, C., and S. Kotz (2003): Statistical Size Distributions in Economics and Actuarial Sciences. Wiley.

Krebs, T. (2003): "Growth and welfare effects of business cycles in economies with idiosyncratic human capital risk," Review of Economic Dynamics, 6, 846-868.

Kydland, F. E., and E. C. Prescott (1982): "Time to Build and Aggregate Fluctuations," Econometrica, 50(6), 1345-1370.

Long, J. B. Jr.., and C. I. Plosser (1983): "Real Business Cycles," Journal of Political Economy, 91(1), 39-69.

Lucas, R. E. Jr.. (1987): Models of Business Cycles. Basil Blackwell Ltd., Oxford.

— (2003): "Macroeconomic Priorities," American Economic Review, 93(1), 1-14.

Maliar, L., and S. Maliar (2004): "Endogenous Growth and Endogenous Business Cycles," Macroeconomic Dynamics, 8, 559-581.

Matsuyama, K. (1999): "Growing Through Cycles," Econometrica, 67(2), 335-347.

(2001): "Growing through Cycles in an Infinitely Lived Agent Economy," Journal of Economic Theory, 100(2), 220-234.

McConnel, M. M., and G. Perez-Quiros (2000): "Output Fluctuations in the United States: What Has Changed Since the Early 1980's?," American Economic Review, 90(5), 14641476 . 
Mendoza, E. G., L. L. Tesar, and A. Razin (1994): "Effective Tax Rates in Macroeconomics: Cross Country Estimates of Tax Rates on Factor Incomes and Consumption," Journal of Monetary Economics, 34, 297 - 323.

Nelson, C. R., and C. I. Plosser (1982): "Trends and Random Walks in Macroeconomic Time Series: Some Evidence and Implications," Journal of Monetary Economics, 10, 139-162.

Padovano, F., and E. Galli (2001): "Tax Rates and Economic Growth in the OECD Countries(1950-1990)," Economic Inquiry, 39, 44-57.

Phillips, K. L., and J. Wrase (2005): "Is Schumpeterian "Creative Destruction" a Plausible Source of Endogenous Real Business Cycles Shocks?," mimeo.

Ramey, G., and V. A. Ramey (1995): "Cross-Country Evidence on the Link Between Volatility and Growth," American Economic Review, 85(5), 1138-1151.

Rosenberg, N. (1994): Exploring the Black Box. Technology, Economics, and History. Cambridge University Press, Cambridge.

Segerstrom, P. S. (1998): "Endogenous Growth without Scale Effects," American Economic Review, 88(5), 1290-1310.

Sennewald, K. (2005): "Controlled Stochastic Differential Equations under Poisson Uncertainty and with Unbounded Utility," University of Dresden, Dep. of Economics, Discussion Paper.

Sennewald, K., and K. Wälde (2005): "Ito's Lemma" and the Bellman equation for Poisson processes: An applied view," University of Dresden, Dep. of Economics, Discussion Paper.

Stock, J. H., and M. W. Watson (2003): "Has the Business Cycle Changed and Why?," NBER Macroeconomics Annual, 2002.

Wälde, K. (1999): “Optimal Saving under Poisson Uncertainty," Journal of Economic Theory, $87,194-217$.

(2002): "The Economic Determinants of Technology Shocks in a Real Business Cycle Model," Journal of Economic Dynamics \& Control, 27, 1-28.

(2005): "Endogenous Growth Cycles," International Economic Review, forthcoming.

Xie, D. (1991): "Increasing Returns and Increasing Rates of Growth," Journal of Political Economy, 99, 429 - 435.

\section{Appendix}

An additional Referees' appendix is available upon request. 
Département des Sciences Économiques de l'Université catholique de Louvain

Institut de Recherches Économiques et Sociales

Place Montesquieu, 3

1348 Louvain-la-Neuve, Belgique 